\title{
The Relevance of Trend Variables for the Prediction of Corporate Crises and Insolvencies
}

\author{
Mario Situm*
}

\begin{abstract}
This study investigated the potential of a specific trend, defined as the relative change of accounting ratios for two consecutive years, to improve the classification accuracy and model performance of insolvency prediction models based on multivariate linear discriminant analysis. The results show that the respective trend can include information from both consecutive years, but this informational content could not be exploited to improve early detection of corporate crises and insolvencies.
\end{abstract}

Keywords: insolvency prediction, discriminant analysis, accounting ratios, trend variables

JEL Classification: C53; G17; G33

\section{Introduction}

The attempts to explain the phenomenon of corporate crisis and the final stage of bankruptcy or insolvency are manifold and the research progress made in these fields over the last 40 years is enormous. Despite this, no valid theory exists for crisis or insolvency prediction which is grounded on already accepted and known financial theories. Further research is justified in this area, as every contribution towards a better understanding of the evolution of corporate crises and bankruptcies increases the likelihood that a theory will be found. This was the motivation behind the study conducted in this paper, where the ability of selected accounting ratios and derived trends was explicitly analysed in an attempt to establish an improved discrimination between bankrupt and non-bankrupt firms. Several trend variables or changes in explanatory variables have been analysed in prior research, generating mixed results. Additionally, it can be seen that the attention given to trend variables was relatively low when compared to the usage of accounting ratios. It is therefore worthwhile to

\footnotetext{
* Mario Situm is at University of Applied Sciences, Kufstein, Austria.
} 
analyse and make an attempt to establish whether trend variables could improve the accuracy of bankruptcy prediction models based on multivariate linear discriminant analysis for the periods two and one year prior to the event of bankruptcy.

The first time that discriminant analysis appeared as a statistical method for the prediction of bankruptcies was in the work of Beaver (1966), who used a univariate approach. An extension of this analysis was put forward by Altman (1968), who introduced a multivariate version. This idea has been followed by several authors (Blum, 1972; Edmister, 1972; Altman et al., 1977; Houghton et al., 1978; Dietrich et al., 2005). Other forms of discriminant analysis (quadratic and non-parametric) were also attempted for the prediction of bankruptcies, but did not outperform the linear version (Altman et al., 1977; Gombola et al., 1987; Barniv et al., 1989; Pacey et al., 1990; Barniv et al., 1992), with the result that they were not considered for model building as part of further studies. Within the work of Ohlson (1980), logistic regression was used to assign probabilities to each company concerning their membership of a certain group. The main advantages of logistic regression are the less stringent pre-conditions when compared to discriminant analysis (normally distributed data and equality of variance-co-variance matrices) and the fact that probabilities for the assignment of an object into a certain category can be obtained.

Another methodological improvement was reached through the use of neural networks, which is a method replicating the complex and non-linear thinking of human brains. Several studies showed that the predictions made using neural networks were superior to the ones obtained by logistic regression and discriminant analysis (Coats et al., 1993; Anandarajan et al., 2001; Charitou et al., 2004; Neves et al., 2006). In many other studies, this superiority was not confirmed as logistic regression provided overly similar results to neural networks (Fanning et al., 1993; Sen et al., 2004; Pompe et al., 2005; Chen et al., 2006; Youn et al., 2010). These three outlined methods remain the most prominent within business failure prediction research (Du Jardin, 2009, p. 44).

Besides these, many other approaches have been tried, with only some being named here for illustrative purposes: Genetic algorithms (Anandarajan et al., 2001; McKee, 2007), recursive partitioning (Frydman et al., 1985; Chen et al, 2006; Huang et al., 2008; Muller et al., 2009), rough set theory and fuzzy logic (Dimitras et al., 1999; Ahn et al., 2000; Lin et al., 2009), support vector machines (Shin et al., 2005; Li et al., 2010; Lin et al., 2011) and option pricing models (Hillegeist et al., 2004; Tsai et al., 2012). None of these approaches clearly outperformed or were demonstrably superior to discriminant analysis, logistic regression and neural networks.

Within this context, accounting ratios were therefore often applied as potential discriminators of business failure and insolvencies, due to their ability to provide early warning signals to predict the potential of a distressed firm to continue towards bankruptcy (Turetsky et al., 2001, p. 339). It also appears that figures from financial statements are informative for some months after their issuance (Piotroski, 2000, p. 1 
-4) in that they provide potential signals that are valuable for predicting insolvencies. In certain cases their informational content is better than market data. As a result, an argument can be made for their application within business failure prediction models (Beaver et al., 1970, 679 - 680). Generally, under an assumption of semi-strong market efficiency, they contain an additional informational content which provides signalling power for the early detection of unfavourable developments (Hopwood et al., 1988b, p. 335 - 337; Setiono et al., 1998; p. 635; Nissim et al., 2003, p. 554; Yip, 2006, p. 505; Lambert et al., 2007, p. 410 - 411; Milburn, 2008, p. 298).

Taking these aspects into consideration, it seems useful to analyse the potential use of accounting ratios and derived trend variables for the purpose of bankruptcy prediction. They are separate from other variables (non-financial variables, market data and economic indicators) and are an interesting aid in the investigation of the behaviour of solvent and insolvent firms. The use of accounting ratios and derived trend variables can help to identify the differences between the two types of firms in order to gain a better understanding about occurrences of crisis, distress and the final outcome of insolvency. This paper shall provide some valuable results with the aim of broadening this understanding and is especially focused on the application of accounting ratios and derived trends for prediction purposes.

The work is organized as follows: Firstly, a literature review of selected papers is provided, analysing trend variables and their discriminatory ability. Secondly, the research design is described, including the database, the dependent variables, the methodology, the research hypothesis, the research questions and a description of the independent variables. Thirdly, a presentation of statistical analyses is given, including descriptive statistics, tests for normal distribution and tests for differences. Fourthly, several models based on multivariate linear discriminant analysis were computed in order to generate prediction models for the assignment of firms into the two groups; bankrupt and non-bankrupt. The models were evaluated using classification accuracy and selected performance measures, where a validation on a separate sample was made. Fifthly, a summary of the results is provided, including a test of the research hypothesis and answers to research questions. Finally, some implications and restrictions of the study are presented, as well as recommendations for future research.

\section{Literature Review}

Within this section, several studies are highlighted which attempted to investigate the potential of different trend variables to assist in the prediction of bankruptcies. It can generally be accepted that accounting ratios are very prominent within research in this field. Du Jardin (2009) analyzed 190 separate papers concerning bankruptcy prediction and found that $93 \%$ of the studies used accounting ratios. The inclusion of trend variables (changes over time of accounting and financial variables) only ap- 
peared in $14 \%$ of the studies. This highlights that the application of such variables within business failure prediction is relatively low when compared to the high number of studies conducted in this field. A similar conclusion was reached during the literature review of this study, where 230 papers related to the topic of business failure/insolvency prediction were analyzed.

One of the first studies analyzing trends for the purpose of bankruptcy prediction was conducted by Blum (1972). The "trend breaks" of income showed importance in discrimination, apart from cash flow/total debt (the best performing ratio within the study of Beaver (1966)). For other trends such as "trend breaks" of net quick assets/ inventory, the standard deviation and slope did not show any discriminatory power. Edmister (1972) concluded that the application of a three year trend of ratios can be a useful predictor of small business failure. Within the study of Altman et al. (1977), stability of earnings as a normalized measure of the standard error estimated over a 10-year-trend of EBIT/TA appeared as an explanatory variable which was suitable to express earning fluctuations. It provided, apart from cumulate profitability, a high explanatory power for the separation between failed and non-failed firms.

Dambolena et al. (1980) used standard deviations of ratios in their prediction models, which could be assigned as a type of trend replicating the volatility of ratios. They found that the additional inclusion of such variables to accounting ratios can increase the prediction accuracy and stability of models over time. Ohlson (1980) used the ratio "CHIN", where net income of the previous year is deducted from the net income of the actual year, and then divided by the sum of the absolute values of both net incomes. This ratio showed a positive sign for the periods two and three years prior to insolvency, which is in contrast to the period one year prior to bankruptcy. A negative sign indicates that an increase of NI/TA from one year to another contributes to a higher logistic value, thereby implying a lower probability of bankruptcy. Such findings are in congruence with expectations. The positive sign for the other two observations periods is explained by the fact that firms improving their NI/ TA need to raise external capital through borrowing, meaning that they are riskier (Ohlson, 1980, p. 122).

The applicability of this ratio was also tested within the work of Begley et al. (1996), where the function of Ohlson (1980) was re-estimated. The variable showed statistical significance within the new data, thereby confirming its relevance for the prediction of bankruptcies. A similar study was conducted by Low et al. (2001). The variable was again found to be statistically significant and was entered within their logit model. They received the same signs as Ohlson (1980), which can be explained by the reasons already outlined in this paper. Additionally, it was argued that cashflow variables should be better indicators for prediction purposes, as firms with a positive increase in net income do not seem to have the ability to generate enough cash-flow to satisfy their debt obligations. 
Within the study of Betts et al. (1987), four trend variables were analysed, measured over a three-year period on total assets, total sales, total number of employees and inventories, but also measuring the change over the previous years. Even if these measures were found to be statistically significant, they did not appear as predictors within their computed discriminant function. As a result, they were not found to be capable of contributing to discrimination. Lau (1987) used stock price trend, trend of capital expenditure and working capital flow trend for prediction purposes. All three were included within the logistic regression function in order to assign firms into five different states. Stock price trend showed a positive sign for the states zero and one, which indicates that stable firms improve their stock price over time, whereas non-stable firms do not. Trend of capital expenditure and working capital flow trend measures were both found to be negative for stable firms respectively, which indicates that a reduction is associated with a lower probability of failure.

Within the study of Abidali et al. (1995), seven trend measures were defined and analysed. Three of these trends were statistically significant and appeared as predictors within a discriminant function to divide between failed and non-failed firms in the construction industry. Non-failed firms showed a positive tax-trend, meaning that firms can only pay taxes when they are profitable. This aspect is associated with lower bankruptcy risk. The earnings after tax trend was also positive for non-failed firms. Such a finding indicates that firms which can increase their earnings are less likely to fail. Finally, the short-term loan trend appeared to be important. Failed firms are dependent on short-term financing and therefore this trend is found to be increasing for failed firms, which is thereby associated with a higher probability of bankruptcy.

Whitaker (1999) analysed several trends as he stated that poor management can be detected by a decline in trends. The trend of industry operating income and the trend containing the relation between the numbers of employees/total assets for two consecutive years were found to be statistically significant. He concluded that an economic improvement is beneficial for recovery and that a growth in industry operating income is a variable which can provide a signal for this point. He also found that firms in distress are more likely to recover when the number of employees is reduced.

Kahya et al. (1999) considered several variables and their changes over time in a cumulative sums (CUSUM) model. They concluded that financially distressed firms experienced a decrease in growth, profitability and fixed assets, but increased their inventory level compared to healthy companies. The application of CUSUM and the inclusion of changes in accounting ratios were seen to be beneficial, as a firm's poor performance could then be flagged by the data and provide early warning signals which are useful for improved prediction. The usefulness of trends was not confirmed within the study of Nam et al. (2000). They defined several trends associated with growth rates in sales, equity, net income and gross value added. Only one variable was statistically significant, but it had insufficient explanatory power, with the result that it was not possible to integrate them within a prediction model as discriminators. 
A methodological progress was achieved by the application of hazard models introduced by Shumway (2001). Here, time-varying covariates can be included so that changes of explanatory variables can be considered. His conclusion was that such an aspect is valuable for prediction purposes and especially interesting in reducing invariance. These results were confirmed by the study of Turetsky et al. (2001). Of particular importance was their finding that the decrease of cash-flows is a good early warning indicator within this context. Platt et al. (2002) analysed several growth ratios for the prediction of financial distress. The variable cash-flow-growth in percentage terms appeared as discriminating variables within their early warning system. An increase in this growth rate was negatively associated with the probability of distress and confirmed the results of Turetsky et al. (2001).

Chi et al. (2006) used sales growth rate and earnings growth rate as potential variables for a model to predict export credit risk. The first ratio was not statistically significant, but was included within a logit model for the period three years prior to bankruptcy. The second variable was also not statistically significant, but appeared within a model for the period two years prior to bankruptcy. The general conclusion of the study was that a decrease in operating revenues results in decreased profits, which in turn leads to a decreased performance. The process of distress was defined as a "downward spiral" in a firm's operating ability and can be reflected in changes in significant variables over a three year period (Chi et al., 2006, p. 23).

Huang et al. (2008) applied a hybrid model for bankruptcy prediction. They selected variables from prior research and obtained a variable-rate for each of them, resulting in several trend variables being computed. The performance of neural networks could be improved with the inclusion of trends, indicating their usefulness in distinguishing between failed and non-failed firms. An opposite result was found by Min et al. (2008), where four growth rates of accounting ratios were analysed concerning their potential discriminatory power. None of the variables could be integrated using data envelopment analysis, meaning that their suitability as discrimination variables could not be confirmed.

Wang et al. (2011) analysed the potential of financial indicators to predict the default of small and medium-sized firms. They investigated the annual growth rate of sales. It was not possible to include the ratio into any logit model as it showed no predictive ability for default risk. Based on this review, it can be seen that the number of studies investigating the ability to use trend variables for prediction purposes is relatively small when compared to the number of studies conducted, which confirms the findings of Du Jardin (2009). Additionally, the use of trend variables as predictors has had mixed success. In certain cases, they seem to be valuable in improving prediction accuracy, but in other cases they were not even considered for model building due to the lack of statistical significance and/or explanatory power. 


\section{Data, Research Design and Variables}

\section{Database and Dependent Variables}

The database of the study included accounting ratios from Austrian firms from different industries for the observation period 2010 to 2012. The year 2012 was set as the insolvency/bankruptcy date and the previous periods were defined as follows:

- 2011: one year prior to insolvency/bankruptcy

- 2010: two years prior to insolvency/bankruptcy

The firms were divided into the states solvent (assigned as 1) and insolvent (assigned as 0 ). These two states were thereby defined as the dependent variables. Within the group of insolvent firms, two subclasses were summarized. The first sub-class contained enterprises which went into bankruptcy in 2012 based on the legal findings of Austrian insolvency law. The second sub-class was set up comprising firms exhibiting a specific indicator, under which they can be assumed to be distressed. A possible definition for distress in this instance is the occurrence of negative earnings for two consecutive years. Such a definition and procedure was also used in prior research (DeAngelo et al., 1990; Platt et al., 2002; Platt et al., 2008; Molina et al., 2009). Solvent firms were negatively defined and were neither insolvent nor distressed. In total, 1,616 firms were identified from the database, for which three consecutive financial statements were available.

No matched pairing was applied within the study, because of a potential choicebased sampling (Zmijewski, 1984, p. 59 - 60; Ward, 1999; p. 170; Platt et al., 2002, p. 186; Skogsvik et al., 2013, p. 29 - 30). In the case of paired samples, the chosen sample does not replicate the true proportions between solvent and insolvent firms which are observable in practice. As insolvencies are indeed a rare event, they carry with them certain characteristics and prior probabilities which are different to solvent cases. In order to detect these characteristics and associated patterns, it is useful to use different proportions between the two types of firms (Thomas et al., 2002, p. 122). Therefore, a proportion similar to previous studies was used within this study (Ohlson, 1980; Zmijewski, 1984; Hillegeist et al., 2004; Chaudhuri, 2013). For the evaluation of model stability and applicability for classification purposes, a validation sample was randomly chosen consisting of 693 firms, where 11 went into bankruptcy, 30 were assigned as distressed and 652 remained non-bankrupt.

Figure 1: Division of firms into different economic states

\begin{tabular}{|l|c|c|}
\hline \multicolumn{1}{|c|}{ Economic state } & Initial sample & Validation sample \\
\hline Insolvent & 26 & 11 \\
\hline Distressed & 70 & 30 \\
\hline Solvent & 1,520 & 652 \\
\hline Total & $\mathbf{1 , 6 1 6}$ & $\mathbf{6 9 3}$ \\
\hline
\end{tabular}




\section{Methodology and Research Design}

The purpose of this study was to develop forecasting models based on linear discriminant analysis, including accounting ratios and trend variables. The additional purpose was to test whether trends can provide additional explanatory power for the early detection of corporate crises and insolvencies. The following procedures were conducted towards these purposes:

1. Descriptive statistics were computed in order to derive measures such as mean, median and standard deviation for the comparison between the two groups.

2. A test for normal distribution of data was applied, in order to recognize whether a parametric or non-parametric test for the differences between the two groups must be applied.

3. In order to detect the most effective discriminating variables, parametric tests were applied for differences in means (t-test) and differences in variances (Levene-Test) and a non-parametric test (U-test).

4. Finally, several discriminant functions were computed, the use of which makes it possible to test the hypothesis and to answer the research questions.

The hypothesis of this work is:

Corporate crises and insolvencies can be much better detected when trends are considered within early warning models.

Additionally, the following research questions should be answered:

1. Which accounting ratios and trends are useful for discrimination between solvent and insolvent firms and for the early detection of crises?

2. Are trend variables more suitable in forecasting potential corporate crises and insolvencies when compared to accounting ratios?

3. Can a combination of accounting ratios and trends increase the classification performance of early warning systems?

\section{Definition of the Trend Variables}

Within this work, the relative change of accounting ratios for two consecutive years was defined as a "trend" and was computed as follows:

$$
\text { Relative } \text { Change }=\text { Trend }=\frac{\left(\text { Ratio }_{t}-\text { Ratio }_{t-1}\right)}{\mid \text { Ratio }_{t-1} \mid}
$$

Similar attempts to define trends have been made in several prior studies (Ohlson, 1980; Bryant, 1984; Lau, 1987; Abidali et al, 1995; Whitaker, 1999; Low et al., 2001). It should be noted that these studies have specific differences to the definitions contained within this work. The difference between the ratios of the two consecutive 
years should provide a direction of change. Therefore, if a firm is deteriorating in equity-ratio, then the sign should be a minus, indicating a reduction of the respective ratio over time. The absolute value of the ratio from the previous year is taken, in order not to "disturb" the direction of the difference between the two consecutive ratios. Such an occurrence could, for example, be imagined for a deterioration of equity ratios from a negative value to a much higher negative value. In such cases, the numerator without absolute value would offset the direction and provide useless signals, with the result that the consideration of the absolute value seems useful.

It is expected that the defined trend can contribute to improved model stability, in order to eliminate the problem of invariance. Empirical results have shown that the inclusion of stability factors (variables which can offset temporary disturbances and volatilities of the economy) can improve the classification accuracy of forecasting models (Dambolena et al., 1980; Betts et al., 1987; Kahya et al. 1999). Several of the variables were seen to be changes not just in ratios, but also trends (Edmister, 1972; Blum, 1974; Lau, 1987; Shumway, 2001; Shin et al., 2005; Neves et al., 2006; Muller et al., 2009; Molina et al., 2009). As the trend is computed using a combination of accounting ratios from two consecutive years, it can also be expected that the information of the previous year is somehow included to a certain degree, which should be helpful in providing more accurate and reliable early warning signals (Dirickx et al., 1994, p. 443 und 449; Kahya et al., 1999, p. 715; Shumway, 2001, p. 102 - 103).

\section{Independent Variables}

Within the literature review it was shown that research into insolvency prediction has a long history. During that time, numerous variables have been analysed. The results generally provide evidence that almost every variable has a certain ability to predict crises and insolvencies (Butera et al., 2006, p. 317; Pretorius, 2008, p. 417). Nevertheless, several variables appeared more often than others, so that it can therefore be assumed that they are more suitable for prediction purposes. Based on a review of 230 papers related to insolvency prediction, 23 potential variables were selected for analysis, and are displayed within Figure 5 in the appendix of this work.

These are also the variables for which the defined trends contained within equation one were computed. The only variable where this was not done is for the age of the firm. The trend for this variable does not make sense, because independent of the observation period, the trend will always be +1 . Therefore, 22 trends were computed as follows:

- Using the ratios from 2010 and 2009, whereas this relative change was assigned as trend 2010

- Using the ratios from 2011 and 2010, whereas this relative change was assigned as trend 2011 


\section{Statistical analyses}

\section{Descriptive Statistics and Test for Normal Distribution}

All analyses were computed for the accounting ratios and trend variables. Descriptive statistics provide a first indication about how solvent and insolvent firms differ. This is complemented by a test for normal distribution of data. This aspect is necessary, because one important pre-condition for the correct application of multivariate linear discriminant analysis is the availability of normally distributed data (Klecka, 1980, p. 61; Subhash, 1996, p. 263; Hopwood et al., 1988a). Nevertheless, a small deviation from normality can be accepted as this aspect does not influence the classification accuracy of the forecasting models all that heavily (Hopwood et al., 1988a; Feldesman, 2002; Silva et al., 2002). Based on the results shown in the Figures 6 and 7 in the appendix, it can be seen that for almost all accounting ratios and trends, the assumption of normality cannot be presumed. The significances are mostly below 5 percent. Therefore, the theoretical pre-condition for the proper application of multivariate linear discriminant analysis is not given. Such a problem has also appeared in various prior studies (Hauschildt et al., 1984; Pacey et al., 1990; Baetge et al., 1992; Chi et al., 2006; Yim et al., 2007; Samad et al., 2009), where this problem was handled differently.

No attempts have been made within this work to improve normality (e.g. outlier deletion, transformation etc.). Firstly, certain deviations from normality are not a big problem for model building and performance (Hopwood et al., 1988a; Feldesman, 2002; Silva et al., 2002). Secondly, another aim of this study was to detect the potential prediction power of trends for the early detection of crises and insolvencies. Therefore, even under non-normality of data, the application of multivariate linear discriminant analysis is justified, as this technique can be used for this purpose (Feldesman, 2002; Neopyhtou et al., 2004; Kim et al., 2006). Thirdly, it can be stated that the application of techniques to replace outliers or the deletion of certain variables could eliminate potentially important information, with the result that a bias is created during the estimation process, which can lead to misleading answers or results (Feldesman, 2002, p. 257 -288). Nevertheless, it must be kept in mind that the classification accuracy and quality of the models will be influenced by this aspect.

The statistics concerning accounting ratios show that the equity-ratio is in both mean and median higher for solvent firms for both observation periods. This ratio deteriorates for insolvent firms as the event of bankruptcy approaches. All ratios associated with profitability (e.g. EBIT/TA, EBITDA/TA, EBIT/S, NI/TA or EBT/TE) show generally higher values for solvent firms. It appears that efficiency on the operational level helps to prevent firms from the likelihood of failure and decreases the probability of insolvency, which is in congruence with findings from prior research 
(Theodossiou et al., 1996, p. 715; Sudarsanam et al., 2001; Molina, 2005, p. 1436 1441; Chen et al., 2006; Yeh et al., 2010; Youn et al., 2010). The associated ratios could therefore be seen as a proxy for the measurement of management effectiveness (Dambolena et al., 1980, p. 1025).

The age of the firm does not seem to be an explanatory variable, because in median both types of firms exhibit similar values. This observation is in contrast to several prior results (Bates, 1990; Chava et al., 2004; Cressy, 2006), but is in congruence with other research findings (Thornhill et al., 2003; Situm, 2014a). The size of the firm (SIZE I and SIZE II) shows differences one year prior to the event of bankruptcy, which indicates that insolvent firms are shrinking in size. Therefore, this variable seems to have a discriminatory power, which is in congruence with results from previous studies (Ohlson, 1980; Chava et al., 2004; Chi et al., 2006; Situm, 2014a).

Concerning trends, it can be concluded that the signs of direction for some variables provide valuable information. The negative change in the ratio CF/TD is in median higher for an insolvent firm for both observation periods. This indicates that firms in financial distress experience more problems repaying their debt with operational cash flow as the event of bankruptcy approaches. A similar observation can be made for accounting ratios, as $\mathrm{CF} / \mathrm{TD}$ is higher in mean and median for solvent firms. More specifically, this means that the debt capacity of the firm is influenced by reduced cash flows (negative cash-flows) with an accompanying increase in debt financing (visible in the increase of TD/TA for insolvent firms). Both aspects together are the drivers that explain why the value of solvent firms reduces as the event of insolvency approaches (Martin et al., 1976, p. 7 - 8; Hong et al., 1978; p. 8).

The reason behind this can be seen in the fact that distressed firms have difficulties adjusting their capital structure levels, due to the very high transaction costs they must bear. The higher the debt ratio is, the higher the cost of financial insolvency (Drobetz et al., 2006, p. 942 - 944; Pindado et al., 2008, p. 379 - 381; Liang et al., 2009 p. 7). The change in equity-ratio (TE/TA) for bankrupt firms is difficult to interpret, because two years prior to bankruptcy it decreased and one year prior to bankruptcy it increased in median again. Such a result would support the findings that distressed firms are disoriented and their behaviour concerning capital structure decisions follows a more random pattern (Pindado et al., 2008, p. 387 - 389).

It is remarkable that measures of profitability (EBIT/TA, NI/TA, EBITDA/TA, EBIT/S) change dramatically for insolvent firms, meaning that they deteriorate in performance due to different aspects. Therefore, it seems that not only profitability as accounting ratio, but also its change delivers information about efficiency problems. A deteriorating profitability could also be associated with an increase in the probability of insolvency (Kahya et al., 1999, p. 341). 


\section{Tests for Differences}

As the test concerning normality mainly showed non-normally distributed variables, a non-parametric approach for the detection of differences seems suitable in order to filter the best discriminating variables (Ho, 2006, p. 357). For this purpose, a U-test was applied (Sachs, 1997, p. 380; Ho, 2006, p. 368). Additionally, tests for differences in mean (t-test) and in variances (Levene-test) were computed for informational purposes. The results for accounting ratios and trends are shown in the Figures 8 and 9 in the appendix of this work. The following interpretations are based on the results of the U-test, as this is the most appropriate decision technique for non-normally distributed variables.

Concerning accounting ratios, it can be seen that many of the variables have predictive power, meaning that they are potentially of interest as early warning indicators. As expected, the age of the firm showed no prediction power and can be omitted from further analysis. It can be concluded that more variables are statistically significant on the 5 percent level one year prior to bankruptcy (19 out of 23) when compared to two years prior to bankruptcy (16 out of 23$)$. This means that the signalling power increases as the event of bankruptcy approaches. Such a finding confirms the results of prior studies (Altman, 1968; Blum, 1974; Altman et al., 1977; Mensah, 1984; Laitinen et al., 2000; Chi et al., 2006; Korol et al., 2011). The relation TD/TE was not statistically significant, which undermines the inability of the gearing-ratio as a potential prediction variable (Situm, 2014b). All the other variables are useful discriminators. This confirms the statement that somehow every variable seems to have some prediction power (Butera et al., 2006, p. 317; Pretorius, 2008, p. 417). It can also be seen that certain variables can lose their signalling power as insolvency approaches $(\mathrm{C} / \mathrm{TA}$ and $\mathrm{C} / \mathrm{S})$, whereas other variables gain explanatory power one year prior to bankruptcy (S/TA, SIZE I, SIZE II, S/TE, GP/TA).

The trends point to the conclusion that less variables contain discriminatory power when compared to accounting ratios. It is also remarkable that the number of potential discriminators is the same for both observation periods (14 out of 22). Here, the aspect of improved signalling for the period nearer to the event of bankruptcy seems to be invalid. Several trends of accounting ratios lose discrimination power as the event of bankruptcy approaches (EBITDA/S, EBT/TE, TE/TD, TE/TA, TD/ TA), whereas others gain in significance (S/TA, SIZE II, TD/TE, GP/TA). Here, it is remarkable to note that the change in size (based on SIZE II) is only an interesting indicator one year prior to bankruptcy (similarly for accounting ratios). Insolvent firms are in both mean and median shrinking much more when compared to solvent firms. Such a decrease in assets could be associated with bankruptcy costs, which are normally not directly observable (Herzog et al., 2008, p. 227). 


\section{Model building}

\section{Computation of Discriminant Functions}

As the number of potential explanatory variables remained high, it was decided to reduce them into some meaningful and useful prediction variables. A multivariate linear discriminant analysis based on Mahlanobis distance was applied for this purpose. Here, a step-wise method was used, so that after the inclusion of all relevant variables, the ones with the highest predictive power should remain, which are also then the ones used to define the linear discriminant functions. As the purpose of this paper is to detect the potential use of trend variables for the prediction of bankruptcies, several linear discriminant functions were computed based on the initial sample selected:

1. Functions for the years 2010 and 2011 only containing accounting ratios

2. Function for the years 2010 and 2011 only containing trends

3. Function for the years 2010 and 2011 combining both accounting ratios and trends

Figure 2: Statistical measures for model building

\begin{tabular}{|l|c|c|c|c|c|c|}
\hline & \multicolumn{2}{|c|}{ AR } & \multicolumn{2}{c|}{ TR } & \multicolumn{2}{c|}{ CM } \\
\hline Parameter & $\mathbf{2 0 1 0}$ & $\mathbf{2 0 1 1}$ & $\mathbf{2 0 1 0}$ & $\mathbf{2 0 1 1}$ & $\mathbf{2 0 1 0}$ & $\mathbf{2 0 1 1}$ \\
\hline Box-M & 639.367 & 6449.686 & 94.196 & 1148.361 & 639.367 & 4782.434 \\
\hline Significance (Box-M) & .000 & 0.000 & .000 & .000 & .000 & .000 \\
\hline Eigenvalue & .027 & .088 & .007 & .022 & .027 & .095 \\
\hline Canonical Correlation & .162 & .284 & .085 & .147 & .162 & .295 \\
\hline Wilks- $\lambda$ & .974 & .919 & .993 & .978 & .974 & .913 \\
\hline Significance (Wilks- $\lambda$ ) & .000 & .000 & .003 & .000 & .000 & .000 \\
\hline
\end{tabular}

$\mathrm{AR}=$ accounting ratio-model (only including accounting ratios), $\mathrm{TR}=$ trend-model (only including trend variables) and $\mathrm{CM}=$ complete model (including both accounting ratios and trend variables). The combined model in 2010 is the same as the accounting ratio model in 2010. With the application of the step-wise method, it was not possible to include trend variables with the already existing accounting ratios in order to improve model quality and prediction accuracy.

As the Box's M-tests provide statistical significance, is must be concluded that variance-co-variance matrices are not equal. The equality is, apart from the normality of data, another theoretical pre-condition for the correct application of linear discriminant analysis (McLachlan, 2004, p. 132; Burns et al., 2008, p. 598; Raykov et al., 2008, p. 337). The degree of influence on model building and classification accuracy cannot be reliably estimated. Nevertheless, the problem seems to be of less importance when samples are large (Burns et al., 2008, p. 598). Within this study, a relatively large sample was taken in comparison to several prior empirical studies (Hauser et al., 2011; Li, 2012; Pervan et al., 2013; Pang et al., 2013), so it can therefore be assumed that the inequality of variance-co-variance matrices will not impact 
that heavily on model building, but could be a factor for unstable results (Feldesman, 2002, p. 257).

All of the models provide statistically significant values of Wilks-Lambda on the 5 percent level. This indicates that they are in a better position to divide between the two types of firms than a random assignment of them into the two states. Nevertheless, the model quality does not appear to be satisfying, as all values for Wilks-Lambda are high. This means that a very high proportion of the variances between the two groups remain unexplained by the models (Burns \& Burns, 2008, p. 599). This aspect may be attributable to the lack of normality of data and the unequal variance-co-variance matrices. It is therefore expected that the derived models will show weaker classification results and a lower model performance. The following discriminant functions were derived, where AR denotes a model containing only accounting ratios, TR defines a model containing only trend variables and CM is a model using a combination of both accounting ratio and trends. The values in parenthesis denote the respective year prior to bankruptcy:

$$
\begin{aligned}
& A R_{(2010)}=2.526 \cdot \frac{N I}{T A}+0.505 \cdot \frac{R E}{T A}+0.073 \\
& A R_{(2011)}=4.238 \cdot \frac{N I}{T A}+0.001 \cdot \frac{S}{T E}+0.565 \cdot \frac{T E}{T A}+0.119 \cdot \frac{E B I T}{S}+0.449 \\
& T R_{(2010)}=0.015 \cdot \Delta \frac{E B I T}{T A}+0.025 \cdot \Delta \frac{T E}{T A}-0,021 \\
& T R_{(2011)}=0.000073 \cdot \Delta \frac{N I}{S}+1.96 \cdot \Delta S I Z E I I+0.002528 \cdot \Delta \frac{E B I T}{S}+0,242 \\
& C M_{(2010)}=A R_{(2010)} \\
& C M_{(2011)}=4.238 \cdot \frac{N I}{T A}+0.415 \cdot \frac{R E}{T A}+0.16 \cdot S I Z E I I+0.001 \cdot \frac{S}{T E}+0.002 \cdot \Delta \frac{E B I T}{S}-1.845
\end{aligned}
$$

\section{Interpretation of the Results}

Based on the signs for the single variables within the equations, it is possible to interpret how solvent and insolvent firms behave. NI/TA was relevant within equations two, three and seven with a positive sign. This implies that firms with a higher profitability are less likely to fail. The same conclusion can be reached for the ratios EBIT/S and $\triangle \mathrm{EBIT} / \mathrm{S}$. These findings confirm the results of prior studies (Theodossiou et al., 1996; Kane et al., 1998; Kahya et al., 1999; Sudarsanam et al., 2001; Molina, 2005; Chen et al., 2006; Yeh et al. 2010). The size of the firm replicated by $\ln (\mathrm{S})$ showed ability for discrimination one year prior to the event of bankruptcy. It appeared as an accounting ratio within $\mathrm{CM}(2011)$, but also as a trend within TR(2011). The positive sign indicates that larger firms and in particular firms growing in size are less likely to fail. This is a result which is in congruence 
with results from prior research (Ohlson, 1980; Chava et al., 2005; Chi et al., 2006; Pervan et al., 2012; Situm, 2014a).

$\triangle$ EBIT/TA appeared as a relevant prediction within the $\mathrm{TR}(2010)$ and it suggests that an improvement in profitability is associated with a lower probability of bankruptcy (Beaver, 1966; Altman et al., 1977; Zmijewski, 1984; Kahya, 1999; McKee, 2007; Sudarsanam et al., 2001; Chava et al., 2004; Chen et al., 2006; Cheng et al., 2006; Pervan et al., 2011; Tsai, 2013). It is a good measure for management efficiency (Dambolena et al., 1980; Pervan et al., 2012) and therefore an interesting variable for prediction purposes.

The ratio RE/TA was relevant within $\mathrm{AR}(2010)$ as well as in $\mathrm{CM}(2011)$. In both cases, a positive sign is visible. This means that firms with a higher value are less likely to fail. This result is also in congruence with results from prior studies (Altman, 1968; Frydman et al., 1985; McKee, 2007; Altman et al., 2010; Hauser et al., 2011). The ability of the ratio RE/TA to act as a proxy for the age of the firm was not confirmed by this study, because the correlation between the age of the firm and RE/ TA was at a very low level (2010: 0.19 and 2011: 0.21) and not statistically significant. Therefore, the findings of other studies could not be confirmed in relation to this aspect (Altman, 1968; Frydman et al., 1985; Chi et al., 2006).

The equity-ratio (TE/TA) was an important predictor within $\mathrm{AR}(2011)$, and the change of the ratio also showed importance within TR(2010). Generally, this means that the higher the equity ratio is, the less likely a firm will be to go bankrupt. Such a result is in congruence with findings from previous research (Pompe et al., 2005; Grunert et al., 2005). Similarly, it can be concluded that firms which improve their equity-ratio are less likely to fail. S/TE denotes the turnover of equity. Higher values are associated with a lower probability of insolvency (Bruse, 1978), which was also found to be the case within this study. This variable is of interest, because it can be seen as a measure of company growth. It can be said that firms which are in a position to generate more sales are therefore more stable. Additionally, this ratio can be associated as a proxy for the measurement of management competencies and competitiveness (Altman, 1968; Platt et al., 1995). The change of NI/S in equation five provides evidence that firms which increase their profit margin are more stable and have a lower probability of bankruptcy.

\section{Evaluation of Model Quality and Performance}

In order to prove model quality, several performance measures were computed (based on Sobehart et al., 2001; Fawcett, 2006; Agarwal et al., 2007; Anderson, 2007). Additionally, the models developed were tested on the validation sample. Within this context, an "outof-sample" and "out-of-time" approach was applied (Ward, 1999, p. 168 - 169; Sobehart et al., 2001, p. 59 - 61). In case of this study, this was conducted as follows: 
- Application of the model of the respective year on the validation sample of the same year (out-of-sample)

- Application of the model of the respective year on the initial and validation sample of the other year (out-of-time)

Models showing a Gini-coefficient below $50 \%$ are not satisfactory and should not therefore be considered (Anderson, 2007, p. 2005). Under this assumption, models including only trend variables and combined models cannot contribute to an improved model building and to higher classification accuracy. Both models containing only accounting ratios provided the best results, as they showed a Gini-coefficient of above 0.5 . Therefore, only the two accounting ratio models are presented within Figure 3. The results of the other functions can be found in the appendix within Figure 10 of this work.

It can be seen that $\operatorname{AR}(2010)$ is the same as $\operatorname{CM}(2010)$. This means that it was not possible to include additional trend variables two years prior to bankruptcy in order to improve model quality and classification accuracy, even if certain trend variables showed a discriminatory ability based on the U-test. This aspect gives a first indication that trend variables do not seem to provide incremental explanatory power for bankruptcies and that they contain informational content which is inferior when compared to accounting ratios.

Figure 3: Performance measures and classification accuracies for accounting ratio models

\begin{tabular}{|c|c|c|c|c|c|c|c|c|}
\hline & \multicolumn{4}{|c|}{ AR (2011) } & \multicolumn{4}{|c|}{ AR (2010) } \\
\hline & \multicolumn{2}{|c|}{2011} & \multicolumn{2}{|c|}{2010} & \multicolumn{2}{|c|}{2011} & \multicolumn{2}{|c|}{2010} \\
\hline & Initial & Valid. & Initial & Valid. & Initial & Valid. & Initial & Valid. \\
\hline Accuracy & 0.901 & 0.859 & 0.918 & 0.890 & 0,862 & 0,840 & 0,834 & 0,823 \\
\hline Type I Error & 0.729 & 0.854 & 0.833 & 0.854 & 0,563 & 0,659 & 0,490 & 0,634 \\
\hline Type II Error & 0.059 & 0.097 & 0.034 & 0.063 & 0,111 & 0,129 & 0,146 & 0,149 \\
\hline F-measure & 0.947 & 0.923 & 0.957 & 0.941 & 0,924 & 0,911 & 0,906 & 0,900 \\
\hline AUC & 0.777 & 0.719 & 0.766 & 0.794 & 0,778 & 0,742 & 0,774 & 0,796 \\
\hline Gini-coeff. & 0.553 & 0.437 & 0.533 & 0.587 & 0,557 & 0,484 & 0,549 & 0,591 \\
\hline AUC & \multicolumn{2}{|c|}{0.759} & \multicolumn{2}{|c|}{0.774} & \multicolumn{2}{|c|}{0.767} & \multicolumn{2}{|c|}{0.779} \\
\hline Gini-coeff. & \multicolumn{2}{|c|}{0.518} & \multicolumn{2}{|c|}{0.549} & \multicolumn{2}{|c|}{0.533} & \multicolumn{2}{|c|}{0.558} \\
\hline AUC & \multicolumn{4}{|c|}{0.766} & \multicolumn{4}{|c|}{0.773} \\
\hline Gini-coeff. & \multicolumn{4}{|c|}{0.533} & \multicolumn{4}{|c|}{0.545} \\
\hline
\end{tabular}

The figures for AR-model (2011) show how the model with accounting ratios classified the two types of firms. It was applied on the initial group (2011), which was the base for development. Additionally, it was applied on the validation group 2011 (out-of-sample validation) and on the initial and validation group 2010 (out-of-time validation). The same was done for the AR-model (2010). There, the model was estimated based on the initial sample (2010). Out-of-sample validation was conducted on validation group (2010) and the out-of-time validation for the whole year 2011. The Gini-coefficient was computed as 2*AUC - 1 (see Agarwal et al., 2007, p. 291). 
Generally, the models including only trend variables showed a weak performance and it can be concluded that they alone are not able to provide an explanation of the occurrences of distress and bankruptcy. The combination of accounting ratios and trends in 2011 was not able to outperform both AR-models. Under these observations, the hypothesis of this work must be fully rejected. The inclusion of trend variables, which are computed based on the definition in this work, cannot provide additionally explanatory power and are therefore neither beneficial for improved model quality nor classification accuracy.

It is interesting to note that the validation of $\mathrm{AR}(2011)$ showed quite similar results in terms of accuracy as the development sample. Type II errors (a solvent firm was assigned as insolvent) were relatively low, but type I errors (an insolvent firm was assigned as solvent) remained high. This aspect is attributable to the threshold of discriminant function, which was set at zero. Firms with values above zero were categorized as solvent; otherwise they were categorized as insolvent. From a practical viewpoint, it is beneficial to minimize type I errors, because these are much more costly (Sobehart, 2001, p. 59; Barniv et al., 2002; p. 503; Paradi et al., 2004, p. 161; Chi et al., 2006, p. 20 - 21; Muller et al., 2009, p. 27). Therefore, the model could be adjusted toward the cut-off point in order to decrease type II error, which could be a task for future research.

Based on AR(2011), it cannot be concluded that the classification accuracy improves as the event of insolvency approaches. The accuracy for the period two years prior to bankruptcy was better than one year prior to bankruptcy (based on the accuracy ratio, but also on Gini-coefficients). The same can be found for AR(2010), when Gini-coefficients are observed. Such a finding does not confirm the general view provided by previous research (Dambolena et al., 1980, p. 1017 - 1024; Mossman et al., 1998, p. 52; Prasad et al., 2005, p. 391). When analysing the TR-models for both years, this aspect can be undermined, because the Gini-coefficients for the period two years prior to bankruptcy were higher than one year prior to bankruptcy.

The validation procedure showed that both accounting models worked reasonably well and that they are able to provide similarly good classification results. The "outof-sample" validation for AR(2011) showed that firms from the validation sample were better classified than the firms from the initial sample. Concerning "out-oftime" validation, one can see that in certain cases a better classification accuracy was possible than for the base year. AR(2010) also showed good results when applied to other samples, although the results are similarly good if not slightly better compared to AR(2011). In both cases, the models showed good stability and provided relatively consistent prediction accuracy. Concerning model performance, it must be stated that AR(2010) seems to be the best prediction model within this work. This is also visible based on the computations of Figure 4. 
Figure 4: Model comparison using z-values

\begin{tabular}{|l|c|c|c|}
\hline Model & AUC & Se(A) & z-value \\
\hline AR (2011) & 0.766 & 0.01706901 & 44.9004487 \\
\hline AR (2010) & 0.773 & 0.01694296 & 45.5965269 \\
\hline
\end{tabular}

$\mathrm{Se}(\mathrm{A})$ denotes the standard deviation of AUC under ROC analysis (Hanley et al., 1982). This can then be used to compute a z-statistic (Hanley et al., 1983). The higher the z-statistic is, the better the performance of the model. Based on the z-values, it can be seen that both models outperformed the proportional chance model. AR (2010) slightly outperformed AR (2011), with the result that both models perform similarly well when discriminating between the two groups of firms.

\section{Summary of Results and Research Questions}

The results of this study show that trend variables, which are computed based on the definition in this work, cannot contribute to improved classification accuracy. Even if these variables carry certain informational content which is useful for discrimination between failed and non-failed firms based on the computations of the U-test, their potential could not be exploited for improved model building. Therefore, the research hypothesis of this work must be rejected and this provides a result which is in contrast to findings from prior research (Blum, 1972; Edmister, 1972; Altman et al., 1977; Dambolena et al., 1980; Ohlson, 1980; Lau, 1987; Abidali et al., 1995; Begley et al., 1996; Whitaker, 1999; Kahya et al., 1999; Low et al., 2001; Shumway, 2001; Turetsky et al., 2001; Wang et al., 2011), but confirms the results of other studies (Betts et al., 1987; Min et al., 2008; Wang et al., 2011). It must be emphasized that an accurate comparison to previous research is limited, as in most cases different computations of trend variables and classes of variables were used.

The research hypothesis of this work was rejected as it was not possible to develop a prediction model based on multivariate linear discriminant analysis, which contained a combination of accounting ratios and trend variables which is superior to a model containing only accounting ratios. Therefore, the results from prior research concerning the usefulness of accounting ratios can be confirmed by this study (Beaver, 1966; Hopwood, 1988b; Setiono, 1998; Turetsky et al., 2001; Nissim et al., 2003; Lambert et al., 2007; Milburn, 2008). During the development of linear discriminant analysis, it was found that the explanatory power of the model is limited, based on the values obtained for Wilks-Lambda. A high proportion of unexplained variances remain in all models. This allows the conclusion to be made that accounting ratios and trends are not sufficient to explain the occurrences of crises and insolvencies and that additional variables, which are not derived from financial statements, are necessary to decrease the unexplained variances. Such a finding confirms the currently accepted view in business failure prediction (Muller et al., 2009; Altman et al., 2010; Madrid-Guijarro et al., 2011; Iazzolino et al., 2013). 
Research question one:

This study revealed that already recognized discriminators (accounting ratios) showed predictive power and that they are able to provide distinction between the two types of firms. These ratios were NI/TA, RE/TA, TE/TE, EBIT/S, EBITDA/S, SIZE II and S/TE. Firms with a higher profitability are less likely to fail (Beaver, 1966; Zmijewski, 1984; Sudarsanam et al., 2001; Tsai, 2013). Higher retained earnings are a sign of stability and this aspect decreases the probability of bankruptcy (Altman, 1968; Altman et al., 1977; Neves et al., 2006; Altman et al., 2010). A higher equity-ratio can be associated with a reduced bankruptcy risk (Pompe et al., 2005; Grunert et al., 2005). Firms which can generate higher turnover of equity (S/TE) are less likely to go into bankruptcy (Bruse, 1978). Finally, firms which are bigger or growing in size, have a lower probability of insolvency (Chancharat et al., 2010; Situm, 2014a). The changes in profitability (EBIT/TA), in equity-ratio (TE/TA), in EBIT-margin $(\mathrm{EBIT} / \mathrm{S})$ and in size $(\ln (\mathrm{S}))$ showed positive signs, indicating that an improvement of these trends is associated with a lower probability of bankruptcy.

Research question two:

The suitability of trend variables, computed as defined in equation one, must be neglected based on the results obtained. Models including only trend variables (models TR(2010) and TR(2011)) were neither able to provide good classification results, nor were they able to deliver high Gini-coefficients. Therefore, they cannot be more suitable than accounting ratios for the prediction of corporate crises and insolvencies. Theoretically, trends should be seen as variables which can provide information about the dynamic development of a firm (Dirickx et al., 1994, p. 443 and 449). Additionally, it could be argued that in order to compute a trend, information from different variables must be combined, so that the new inherent information in the trend variables should increase classification accuracy (Shumway, 2001; Situm, 2008, p. 43).

Even if trends show correlations to different accounting ratios of the two consecutive years, it is not possible to exploit this aspect for the purpose of model building. A reason for this could be that the correlations are not "perfect", meaning that perhaps potentially important portions of information relevant to a better discrimination between the two groups of firms were not included within the trend variables. In addition to that, the computation of the trend based on equation one can be defined as a data transformation process, which can create a bias in informational content, as the information originally contained within the accounting variables was not fully replicated within the newly computed trend variable.

Research question three:

The inclusion of trend variables in models already containing accounting ratios could not help to improve classification accuracy and model quality. For the year 
2010, trend variables were totally irrelevant for the complete model (CM(2010)). This means that it was not possible to additionally include any of the trends in order to improve the model. For the year 2011, an inclusion of one trend variable was possible, but this consideration did not improve classification accuracy and model performance. Consequently, it must be concluded that a combination of accounting ratios and trend variables cannot increase the classification performance of early warning systems.

\section{Implications, Restrictions and Recommendations for Future Research}

The results provide evidence that the application of accounting ratios for the construction of prediction models seems useful, as they showed relatively good classification results even if the data was non-normally distributed (Hopwood et al., 1988a, p. 335 - 337; Turetsky et al., 2001, p. 339; Nissim et al., 2003, p. 554; Lambert et al., 2007, p. 410 - 411). The relevance of trend variables was not given, as the definition of the trend which was used was not suitable for the task of prediction. This was because the "transformation" eliminated certain information which had been included in the original accounting ratios, and which were probably relevant for a better differentiation between the two types of firms. Therefore, it must be concluded that the definition of the trend from equation one does not seem to be suitable and that there is a need for a "transformation" which does not bias the original information. The newly computed trend should carry a higher or almost equal informational content when compared to the variables on which the trend is derived (Schneider, 1995, p. 1490; Situm, 2008, p. 43 - 44).

A problem may be identified in the non-normality of data and the unequal variance-co-variance matrices, which are two theoretical pre-conditions for the application of linear discriminant analysis, although the latter does not seem to be that relevant for big sample sizes. This aspect was taken into account due to the fact that the purpose of this study was to analyse the potential contribution of trend variables derived from accounting ratios for the prediction of bankruptcies. The application of linear discriminant analysis can be used for this task, even if the pre-conditions are violated. Nevertheless, the model quality and classification accuracy were undoubtedly influenced, but the variable selection process using step-wise methods was also affected. Based on these findings, the following interesting remarks can be made:

1. Non-normality of data seems to affect the informational content of trends much more than accounting ratios. This means that the potential of trends to improve model quality and classification accuracy was reduced by this finding, which was not expected from a theoretical viewpoint. Trends were computed based on data from two consecutive years, meaning that they should contain information from 
both years and this should be beneficial for improved discrimination (Dirickx et al., 1994). Therefore, this aspect was not confirmed by the results obtained.

2. Although non-normality was taken as a given, the models remained quite stable. The models which were derived based on accounting ratios showed a relatively high degree of accuracy across the development sample and all validation samples. The conclusion from this finding is that linear discriminant analysis functions relatively well, even if the assumption of normality is, to a certain degree, not a given. This finding confirms the results from prior research (Hopwood et al., 1988a; Silva et al., 2002; Feldesman, 2002). It can therefore be used as a tool to detect potentially relevant discriminators, so that its application seems justified even if non-normal data is used for model building (Feldesman, 2002; Neophytou et al., 2004; Kim et al., 2006).

3. The values of Wilks-Lamdba indicate that many aspects of the relation between the dependent and independent variables remain unexplained. This indicates that the sole consideration of the accounting ratio appears insufficient in explaining the differences between bankrupt and non-bankrupt firms. This aspect may, to a certain degree, be attributable to the non-normality of data. But the majority of the unexplained proportion is more likely to be dependent on other factors, not investigated within this study, which are necessary to obtain a more powerful and explanatory model. Such a finding confirms the currently recognized view within research (Grunert et al., 2005; Muller et al., 2009; Altman et al., 2010; Iazzolini et al., 2013).

Additionally, the definition of the insolvent group may have created a certain bias, which affected the ability of the independent variables with respect to discrimination between the two groups of firms. Bankrupt firms and distressed firms were included within the group of insolvent firms, where distress was defined as the occurrence of losses for two consecutive years. Although such a definition follows the results accepted from prior studies, such a mix of different types of firms could create a bias, which is the reason for the weaker discrimination ability of prediction models. Nevertheless, it seems that both types of solvent firms appear to have similarities. They exhibit similar behaviour and are, in many cases, difficult to distinguish from each other (Gilbert et al., 1990; Wilson et al., 1995), so an argument can be made for mixing them together.

Several interesting topics and questions remain for future research. Firstly, different computations of trend could be attempted, in order to test their ability to act as a predictor for distress and bankruptcy. Perhaps there are certain "transformations" of ratios to establish trend variables which would not create an information bias and would restore the informational content of the original variables used for the computation of the trend. Secondly, a new sample could be used, where all variables are adjusted using different techniques, in order to guarantee normality of data. Using 
this new sample, the research design of this study should be replicated and the results obtained can be compared with the results of this study. Finally, another model technique (logistic regression and/or decision tree analysis) could be applied, in order to validate the results of linear discriminant analysis and to test whether better model quality and classification accuracy can be obtained. Perhaps under such models, the inclusion of trend variables based on the definition of this work can provide incremental prediction accuracy.

\section{Appendix}

Figure 5: Independent variables selected for research based on literature review

\begin{tabular}{|l|l|}
\hline Accounting ratio/trend & Computation \\
\hline AGE*) & Age of the firm in years \\
\hline CF/TD & $\begin{array}{l}\text { Cash Flow (Net Income + Depreciation)/Total } \\
\text { Debt }\end{array}$ \\
\hline NI/TA & Net Income/Total Assets \\
\hline EBIT/TA & EBIT/Total Assets \\
\hline S/TA & Sales/Total Assets \\
\hline RE/TA & $\begin{array}{l}\text { Retained Earnings (Cumulated Earnings + } \\
\text { Reserves/Total Assets }\end{array}$ \\
\hline NI/S & Net Income/Sales \\
\hline C/TA & Cash/Total Assets \\
\hline SIZE I & Ln(Total Assets) \\
\hline EBITDA/S & EBITDA/Sales \\
\hline SIZE II & Ln(Sales) \\
\hline C/S & Cash/Sales \\
\hline EBT/TE & Earnings before Taxes /Total Equity \\
\hline S/TE & Sales/Total Equity \\
\hline TD/TE & Total Debt/Total Equity \\
\hline TE/TD & Total Equity/Total Debt \\
\hline TE/TA & Total Equity/Total Assets \\
\hline TD/TA & Total Debt/Total Assets \\
\hline EBITDA/TA & EBITDA/Total Assets \\
\hline EBIT/S & EBIT/Sales \\
\hline EBITDA/TD & EBIT/Total Debt \\
\hline GP/TA & Gross Profit/Total Assets \\
\hline EBIT/TD & EBIT/Total Debt \\
\hline & \\
\hline
\end{tabular}

*) For the age of the firm no trend was computed. 
Figure 6: Descriptive statistics and tests for normal distribution for accounting ratios Values in bold denote normally distributed variables on the 5 percent level

\begin{tabular}{|c|c|c|c|c|c|c|c|c|c|}
\hline \multirow[b]{3}{*}{ Ratio } & \multirow[b]{3}{*}{ State } & \multicolumn{4}{|c|}{2011} & \multicolumn{4}{|c|}{2010} \\
\hline & & \multirow{2}{*}{$\begin{array}{c}\begin{array}{c}\text { Test for } \\
\text { Normality } \\
\text { of Data }\end{array} \\
\text { KS- } \\
\text { Statistic }\end{array}$} & \multicolumn{3}{|c|}{ Descriptive Statistics } & \multirow{2}{*}{\begin{tabular}{|c|}
$\begin{array}{c}\text { Test for } \\
\text { Normality } \\
\text { of Data }\end{array}$ \\
KS- \\
Statistic
\end{tabular}} & \multicolumn{3}{|c|}{ Descriptive Statistics } \\
\hline & & & Mean & Median & $\begin{array}{c}\text { Stand.- } \\
\text { Deviation }\end{array}$ & & Mean & Median & $\begin{array}{c}\text { Stand.- } \\
\text { Deviation }\end{array}$ \\
\hline \multirow{2}{*}{ AGE } & 0 & .000 & 22.146 & 13.500 & 21.679 & .000 & 21.146 & 12.500 & 21.679 \\
\hline & 1 & .000 & 24.128 & 13.500 & 27.939 & .000 & 23.128 & 12.500 & 27.939 \\
\hline \multirow{2}{*}{$\mathrm{CF} / \mathrm{TD}$} & 0 & .000 & -.205 & -.005 & 1.302 & .000 & -.041 & .019 & .929 \\
\hline & 1 & .000 & .231 & .116 & .835 & .000 & .281 & .118 & 1.741 \\
\hline \multirow{2}{*}{ NI/TA } & 0 & .000 & -.175 & -.040 & .543 & .000 & -.079 & -.017 & .504 \\
\hline & 1 & .000 & .039 & .029 & .165 & .000 & .049 & .034 & .166 \\
\hline \multirow{2}{*}{ EBIT/TA } & 0 & .000 & -.089 & -.009 & .282 & .000 & .002 & .001 & .107 \\
\hline & 1 & .000 & .069 & .045 & .320 & .000 & .063 & .043 & .175 \\
\hline \multirow{2}{*}{ S/TA } & 0 & .000 & 1.417 & .568 & 3.379 & .000 & 1.557 & 1.118 & 1.340 \\
\hline & 1 & .000 & 1.399 & .915 & 2.896 & .000 & 1.379 & .990 & 1.353 \\
\hline \multirow{2}{*}{ RE/TA } & 0 & .000 & -.666 & -.002 & 4.116 & .000 & -.228 & .008 & 1.321 \\
\hline & 1 & .000 & .075 & .080 & .436 & .000 & .091 & .106 & .547 \\
\hline \multirow{2}{*}{$\mathrm{NI} / \mathrm{S}$} & 0 & .000 & -3.445 & -.065 & 17.321 & .000 & -.171 & -.014 & 1.359 \\
\hline & 1 & .000 & -.619 & .034 & 22.182 & .000 & .043 & .035 & 9.767 \\
\hline \multirow{2}{*}{$\mathrm{C} / \mathrm{TA}$} & 0 & .000 & .091 & .016 & .159 & .000 & .046 & .019 & .065 \\
\hline & 1 & .000 & .089 & .029 & .134 & .000 & .082 & .030 & .128 \\
\hline \multirow{2}{*}{ SIZE I } & 0 & .013 & 15.309 & 15.561 & 2.345 & .000 & 16.300 & 16.257 & 1.771 \\
\hline & 1 & .000 & 15.873 & 15.914 & 1.684 & .000 & 16.370 & 16.224 & 1.684 \\
\hline \multirow{2}{*}{ EBITDA/S } & 0 & .000 & -.622 & .048 & 4.084 & .000 & .066 & .039 & .187 \\
\hline & 1 & .000 & .067 & .110 & 1.467 & .000 & .075 & .096 & 1.444 \\
\hline \multirow{2}{*}{ SIZE II } & 0 & .003 & 14.517 & 15.073 & 2.635 & .000 & 16.336 & 16.297 & 2.015 \\
\hline & 1 & .000 & 15.555 & 15.635 & 1.820 & .000 & 16.146 & 16.061 & 1.659 \\
\hline \multirow[b]{2}{*}{$\mathrm{C} / \mathrm{S}$} & 0 & .000 & .585 & .033 & 2.078 & .000 & .049 & .018 & .097 \\
\hline & 1 & .000 & 1.147 & .034 & 21.246 & .000 & .213 & .032 & 1.506 \\
\hline & 0 & .000 & .072 & -.021 & 1.609 & .000 & -.053 & -.031 & 1.488 \\
\hline EBT/TE & 1 & .000 & .307 & .121 & 7.519 & .000 & .437 & .141 & 7.214 \\
\hline & 0 & .000 & -123.102 & 2.459 & 1367.715 & .000 & 9.031 & 3.681 & 44.645 \\
\hline S/TE & 1 & .000 & 17.076 & 1.351 & 290.755 & .000 & 16.974 & 2.909 & 208.488 \\
\hline TD/TF & 0 & .000 & 1.172 & 1.351 & 66.932 & .000 & 4.053 & 2.575 & 22.108 \\
\hline $10 / 1 \mathrm{E}$ & 1 & .000 & 7.820 & 1.851 & 83.491 & .000 & 7.175 & 1.920 & 92.421 \\
\hline TE/TD & 0 & .000 & .801 & .204 & 2.192 & .000 & .401 & .257 & .581 \\
\hline $1 \mathrm{E} / \mathrm{ID}$ & 1 & .000 & 3.420 & .363 & 39.919 & .000 & 5.668 & .409 & 123.558 \\
\hline TE/TA & 0 & .000 & -.236 & .170 & 3.125 & .000 & .083 & .204 & 1.056 \\
\hline 1E/1A & 1 & .000 & .284 & .266 & .381 & .000 & .299 & .290 & .496 \\
\hline TD/TA & 0 & .000 & 1.236 & .830 & 3.125 & .000 & .917 & .796 & 1.056 \\
\hline 1D/1A & 1 & .000 & .716 & .733 & .381 & .000 & .702 & .710 & .499 \\
\hline EBITDA/ & 0 & .000 & -.032 & .033 & .285 & .000 & .046 & .040 & .113 \\
\hline $\mathrm{TA}$ & 1 & .000 & .120 & .097 & .323 & .000 & .107 & .085 & .180 \\
\hline & 0 & .000 & -2.148 & $\begin{array}{l}.018 \\
\end{array}$ & 14.342 & .000 & -.007 & .001 & .133 \\
\hline EBIT/S & 1 & .000 & -.026 & .049 & 1.459 & .000 & .010 & .048 & 1.442 \\
\hline EBITDA/ & 0 & .000 & -.032 & .031 & .479 & .000 & .078 & .049 & .232 \\
\hline & 1 & .000 & .261 & .137 & .917 & .000 & .323 & .123 & 4.375 \\
\hline & 0 & .000 & 2.207 & .736 & 6.603 & .000 & 2.251 & 1.323 & 2.269 \\
\hline GP/TA & 1 & .000 & 2.024 & 1.066 & 5.112 & .000 & 2.029 & 1.119 & 2.436 \\
\hline & 0 & .000 & -.109 & $\begin{array}{l}-.013 \\
\end{array}$ & .479 & .000 & .019 & .002 & .212 \\
\hline ЕВIT/ТD & 1 & .000 & .162 & .062 & .853 & .000 & .242 & .060 & 4.372 \\
\hline
\end{tabular}


Figure 7: Descriptive statistics and tests for normal distribution for trends Values in bold denote normally distributed variables on the 5 percent level

\begin{tabular}{|c|c|c|c|c|c|c|c|c|c|}
\hline \multirow[b]{3}{*}{ Ratio } & \multirow[b]{3}{*}{ State } & \multicolumn{4}{|c|}{2011} & \multicolumn{4}{|c|}{2010} \\
\hline & & \multirow{2}{*}{$\begin{array}{c}\begin{array}{c}\text { Test for } \\
\text { Normality } \\
\text { of Data }\end{array} \\
\text { KS- } \\
\text { Statistic }\end{array}$} & \multicolumn{3}{|c|}{ Descriptive Statistics } & \multirow{2}{*}{$\begin{array}{c}\begin{array}{c}\text { Test for } \\
\text { Normality } \\
\text { of Data }\end{array} \\
\begin{array}{c}\text { KS- } \\
\text { Statistic }\end{array}\end{array}$} & \multicolumn{3}{|c|}{ Descriptive Statistics } \\
\hline & & & Mean & Median & $\begin{array}{c}\text { Stand.- } \\
\text { Deviation }\end{array}$ & & Mean & Median & $\begin{array}{c}\text { Stand.- } \\
\text { Deviation }\end{array}$ \\
\hline \multirow{2}{*}{$\mathrm{CF} / \mathrm{TD}$} & 0 & .000 & -3.079 & -.414 & 30.565 & .000 & 1.947 & -.910 & 21.663 \\
\hline & 1 & .000 & 7.156 & -.035 & 99.703 & .000 & 13.025 & .049 & 329.943 \\
\hline \multirow{2}{*}{ NI/TA } & 0 & .000 & -10.517 & -.701 & 74.714 & .000 & -11.482 & -1.327 & 66.289 \\
\hline & 1 & .000 & 9.172 & -.049 & 121.377 & .000 & 5.115 & .120 & 86.781 \\
\hline \multirow{2}{*}{ EBIT/TA } & 0 & .000 & -9.296 & -.655 & 56.800 & .000 & -.832 & -.917 & 9.322 \\
\hline & 1 & .000 & 6.169 & .042 & 97.721 & .000 & 2.932 & .007 & 16.044 \\
\hline \multirow{2}{*}{$\mathrm{S} / \mathrm{TA}$} & 0 & .000 & 1.358 & -.465 & 5.929 & .000 & 1.745 & .069 & 6.455 \\
\hline & 1 & .000 & 35.810 & -.090 & 1016.610 & .000 & 2.318 & -.205 & 17.032 \\
\hline \multirow{2}{*}{ RE/TA*) } & 0 & .000 & -10.235 & -.281 & 55.788 & .000 & -6.296 & -.665 & 36.600 \\
\hline & 1 & .000 & -12.858 & -.073 & 762.557 & .000 & 240639.784 & .028 & 9381287,259 \\
\hline \multirow{2}{*}{$\mathrm{NI} / \mathrm{S}$} & 0 & .000 & -185.997 & -1.123 & 1229.118 & .000 & -20.584 & -1.214 & 124.405 \\
\hline & 1 & .000 & -76.372 & -.137 & 3270.780 & .000 & 45.373 & .423 & 2890.558 \\
\hline \multirow{2}{*}{$\mathrm{C} / \mathrm{TA}$} & 0 & .000 & 38.208 & .590 & 172.133 & .000 & 47.780 & -.004 & 279.685 \\
\hline & 1 & .000 & 6349.044 & -.020 & 230374.729 & .000 & 97.735 & .046 & 1224.035 \\
\hline \multirow{2}{*}{ SIZE I } & 0 & .018 & -.047 & -.052 & .196 & .466 & -.012 & -.015 & .138 \\
\hline & 1 & .000 & -.020 & -.023 & .149 & .000 & .005 & -.005 & .157 \\
\hline \multirow{2}{*}{ EBITDA/S } & 0 & .000 & -104.591 & .187 & 943.633 & .000 & .152 & -.574 & 19.539 \\
\hline & 1 & .000 & 6.159 & .162 & 125.290 & .000 & 5.175 & .267 & 164.480 \\
\hline \multirow{2}{*}{ SIZE II } & 0 & .000 & -.092 & -.082 & .231 & .059 & -.011 & -.018 & .153 \\
\hline & 1 & .000 & -.025 & -.021 & .164 & .000 & -.008 & -.023 & .166 \\
\hline \multirow{2}{*}{$\mathrm{C} / \mathrm{S}$} & 0 & .000 & 74.492 & .421 & 231.099 & .000 & 33.102 & -.376 & 166.469 \\
\hline & 1 & .000 & 6173.154 & -.098 & 156398.803 & .000 & 293.319 & .205 & 6322.947 \\
\hline \multirow{2}{*}{ EBT/TE } & 0 & .000 & 9.122 & .096 & 72.369 & .000 & -5.556 & -1.034 & 66.755 \\
\hline & 1 & .000 & 11.400 & -.053 & 237.813 & .000 & 7.097 & .101 & 196.641 \\
\hline \multirow{2}{*}{$\mathrm{S} / \mathrm{TE}$} & 0 & .000 & -75.468 & -.798 & 774.843 & .000 & 3.454 & -.045 & 17.399 \\
\hline & 1 & .000 & 41.549 & -.091 & 1635.204 & .000 & 8.782 & -.120 & 88.697 \\
\hline TD/TF & 0 & .000 & 7.563 & -.347 & 112.814 & .000 & -11.024 & .221 & 138.073 \\
\hline TD/TE & 1 & .000 & -274.229 & -.014 & 13011.792 & .000 & 3.938 & .059 & 49.734 \\
\hline & 0 & .000 & 13.509 & .038 & 90.143 & .000 & .540 & -.491 & 13.183 \\
\hline TE/TD & 1 & .000 & 16.074 & -.214 & 179.510 & .000 & 46.228 & .017 & 1133.089 \\
\hline & 0 & .000 & .345 & .027 & 13.014 & .000 & -1.257 & -.350 & 16.467 \\
\hline TE/TA & 1 & .000 & 4.992 & -.150 & 92.860 & .000 & 1.694 & .012 & 10.190 \\
\hline TD/TA & 0 & .000 & .818 & -.004 & 4.918 & .000 & 1.665 & .148 & 6.979 \\
\hline TD/TA & 1 & .000 & 4.557 & .053 & 112.943 & .000 & .822 & -.003 & 12.928 \\
\hline EBITDA/ & 0 & .000 & -1.023 & -.381 & 9.213 & .000 & -1.986 & -.478 & 21.118 \\
\hline & 1 & .000 & 14.715 & .179 & 295.990 & .000 & 2.715 & -.053 & 21.917 \\
\hline & 0 & .000 & -107.356 & -.479 & 600.636 & .000 & -.468 & -.898 & 11.246 \\
\hline EBIT/S & 1 & .000 & -.664 & .020 & 160.606 & .000 & -5.015 & .235 & 378.877 \\
\hline EBITDA/ & 0 & .000 & -.115 & -.337 & 10.982 & .000 & -1.014 & -.615 & 17.908 \\
\hline & 1 & .000 & 8.180 & .063 & 77.114 & .000 & 4.571 & -.042 & 39.412 \\
\hline & 0 & .000 & 1.758 & -.475 & 7.474 & .000 & 2.342 & .018 & 7.640 \\
\hline GP/TA & 1 & .000 & 42.188 & -.097 & 1107.576 & .000 & 3.629 & -.260 & 28.001 \\
\hline & 0 & .000 & -5.408 & -.615 & 29.271 & .000 & .140 & -.943 & 20.260 \\
\hline & 1 & .000 & 7.283 & .014 & 68.624 & .000 & 5.002 & -.003 & 34.334 \\
\hline
\end{tabular}

*) The mean and standard deviation for RE/TA in 2010 are extremely high. This aspect is attributable to one single case, having a RETA in 2009 of $-2.29210^{-10}$ and in 2010 of 0.0838. 
Figure 8: Tests for differences for accounting ratios Values in bold denote statistically significant differences on the 5 percent level

\begin{tabular}{|c|c|c|c|c|c|c|c|}
\hline & \multicolumn{3}{|c|}{2011} & \multicolumn{3}{|c|}{2010} \\
\hline & & \multicolumn{3}{|c|}{ Tests for Differences } & \multicolumn{3}{|c|}{ Tests for Differences } \\
\hline Ratio & State & t-Test & Levene-Test & U-Test & t-Test & Levene-Test & U-Test \\
\hline \multirow{2}{*}{ AGE } & 0 & \multirow{2}{*}{0.495} & \multirow{2}{*}{0.149} & \multirow{2}{*}{0.971} & \multirow{2}{*}{0.495} & \multirow{2}{*}{0.149} & \multirow{2}{*}{0.971} \\
\hline & 1 & & & & & & \\
\hline \multirow{2}{*}{$\mathrm{CF} / \mathrm{TD}$} & 0 & \multirow{2}{*}{0.000} & \multirow{2}{*}{0.078} & \multirow{2}{*}{0.000} & \multirow{2}{*}{0.073} & \multirow{2}{*}{0.622} & \multirow{2}{*}{0.000} \\
\hline & 1 & & & & & & \\
\hline \multirow{2}{*}{ NI/TA } & 0 & \multirow[t]{2}{*}{0.000} & \multirow[t]{2}{*}{0.000} & \multirow[t]{2}{*}{0.000} & 0.000 & 0.001 & 0.000 \\
\hline & 1 & & & & 0.000 & 0.001 & \\
\hline EBIT/TA & 0 & 0.000 & 0.066 & 0.000 & 0.001 & 0.337 & 0.000 \\
\hline EDI1/1A & 1 & 0.000 & & & & & \\
\hline S/TA & 0 & 0.953 & 0.210 & 0.003 & 0.212 & 0.387 & 0.133 \\
\hline $\mathrm{S} / 1 \mathrm{~A}$ & 1 & 0.953 & 0.210 & $0.00 \mathrm{~s}$ & & & \\
\hline RE/TA & 0 & 0.000 & 0.000 & 0.000 & 0.000 & 0.000 & 0.000 \\
\hline & 1 & & & & & & \\
\hline $\mathrm{NI} / \mathrm{S}$ & 0 & 0.221 & 0.044 & 0.000 & 0.830 & 0.688 & 0.000 \\
\hline & 0 & & & & & & \\
\hline C/TA & 1 & 0.878 & 0.130 & 0.268 & 0.007 & 0.000 & 0.038 \\
\hline SIZE I & 0 & 0002 & 0000 & 0028 & 0691 & 0607 & 0.956 \\
\hline SIZE 1 & 1 & 0.002 & 0.000 & 0.028 & & $0.60 /$ & 0.956 \\
\hline EBITDA/S & 0 & 0.000 & 0.000 & 0.000 & 0.950 & 0.559 & 0.000 \\
\hline & 1 & & & & & & \\
\hline SIZE II & 0 & 0.000 & 0.000 & 0.000 & 0.284 & 0.086 & 0.242 \\
\hline & 1 & & & & & 0.000 & \\
\hline $\mathrm{C} / \mathrm{S}$ & 0 & 0.796 & 0.611 & 0.885 & 0.287 & 0.115 & 0.005 \\
\hline & 1 & & & & & & \\
\hline EBT/TE & 0 & 0.759 & 0.791 & 0.000 & 0.506 & 0.558 & 0.000 \\
\hline & 1 & & & & & & \\
\hline $\mathrm{S} / \mathrm{TE}$ & 0 & 0.002 & 0.000 & 0,000 & 0.709 & 0.596 & 0.497 \\
\hline & 1 & & 0.000 & 0.000 & & & 0.47 \\
\hline TD/TE & 0 & 0.445 & 0.911 & 0228 & 0741 & 0622 & 0.271 \\
\hline & 1 & $0.44 \mathrm{~J}$ & 0.711 & 0.220 & 0.171 & 0.022 & \\
\hline TE/TD & 0 & 0.521 & 0.295 & 0.015 & 0.676 & 0.471 & 0.000 \\
\hline & 1 & 0.021 & & & 0.070 & & \\
\hline $\mathrm{TE} / \mathrm{TA}$ & 0 & 0.000 & 0.000 & 0.014 & 0.000 & 0.062 & 0.000 \\
\hline & 1 & & & & & & \\
\hline TD/TA & $\frac{0}{1}$ & 0.000 & 0.000 & 0.014 & 0.000 & 0.062 & 0.000 \\
\hline EBITDA/TA & 0 & 0.000 & 0.138 & & & & 0.000 \\
\hline EBIIDA/IA & 1 & 0.000 & 0.138 & 0.000 & 0.001 & 0.319 & 0.000 \\
\hline EBIT/S & 0 & 0.000 & 0.000 & 0.000 & 0.908 & 0.507 & 0.000 \\
\hline & 1 & & & & & & \\
\hline EBITDA/TD & $\frac{0}{1}$ & 0.002 & 0.317 & 0.000 & 0.584 & 0.531 & 0.000 \\
\hline GP/TA & 0 & 0739 & 0144 & 0005 & 0385 & 0792 & 0118 \\
\hline UP/IA & 1 & 0.139 & 0.144 & 0.000 & 0.585 & 0.192 & 0.118 \\
\hline EBIT/TD & 0 & 0.002 & 0.609 & 0.000 & 0.618 & 0.550 & 0.000 \\
\hline & 1 & & & & & & \\
\hline
\end{tabular}


Figure 9: Tests for differences for trends Values in bold denote statistically significant differences on the 5 percent level

\begin{tabular}{|c|c|c|c|c|c|c|c|}
\hline & \multirow{2}{*}{\multicolumn{3}{|c|}{2011}} & & & \\
\hline & & & & & \multicolumn{3}{|c|}{2010} \\
\hline & & \multicolumn{3}{|c|}{ Test for Differences } & \multicolumn{3}{|c|}{ Test for Differences } \\
\hline Ratio & State & t-Test & Levene-Test & U-Test & t-Test & Levene-Test & U-Test \\
\hline \multirow{2}{*}{$\mathrm{CF} / \mathrm{TD}$} & 0 & \multirow{2}{*}{0.316} & \multirow{2}{*}{0.840} & \multirow{2}{*}{0.000} & \multirow{2}{*}{0.742} & \multirow{2}{*}{0.621} & \multirow{2}{*}{0.000} \\
\hline & 1 & & & & & & \\
\hline \multirow{2}{*}{ NI/TA } & 0 & \multirow{2}{*}{0.117} & \multirow{2}{*}{0.833} & \multirow{2}{*}{0.000} & \multirow{2}{*}{0.066} & \multirow{2}{*}{0.175} & \multirow{2}{*}{0.000} \\
\hline & 1 & & & & & & \\
\hline \multirow{2}{*}{ EBIT/TA } & 0 & \multirow{2}{*}{0.125} & \multirow{2}{*}{0.785} & 0.000 & 0.023 & 0.135 & 0.000 \\
\hline & 1 & & & & & & \\
\hline S/TA & 0 & 0740 & 0,536 & 0002 & 0743 & 0453 & 0110 \\
\hline $\mathrm{S} / 1 \mathrm{~A}$ & 1 & 0.140 & 0.530 & 0.002 & 0.145 & 0.453 & 0.119 \\
\hline $\mathrm{RE} / \mathrm{TA}$ & 0 & 0.973 & 0.713 & 0.002 & 0.802 & 0.615 & 0.000 \\
\hline КЕ/ $1 \mathrm{~A}$ & 1 & 0.971 & 0.115 & 0.002 & 0.002 & 0.015 & 0.000 \\
\hline $\mathrm{NI} / \mathrm{S}$ & 0 & 0.744 & 0.640 & 0.000 & 0.823 & 0.555 & 0.000 \\
\hline & 1 & & & & & & \\
\hline C/TA & 0 & 0.788 & 0.598 & 0.657 & 0690 & 0.473 & 0441 \\
\hline & 1 & 0.100 & 0.090 & 0.051 & 0.090 & $0.4 / 1$ & 0.441 \\
\hline SIZE I & 0 & 0.091 & 0.007 & 0.059 & 0.286 & 0.351 & 0.463 \\
\hline & 1 & & & & & & \\
\hline EBITDA/S & 0 & 0,000 & 0.000 & 0143 & 0765 & 0.478 & 0.000 \\
\hline EBIIDA/S & 1 & & 0.000 & & 0.105 & $0.4 / 0$ & 0.000 \\
\hline SIZE II & 0 & 0.000 & 0,000 & 0.000 & 0.887 & 0.712 & 0711 \\
\hline & 1 & & & & & & \\
\hline $\mathrm{C} / \mathrm{S}$ & 0 & 0.703 & 0.453 & 0.055 & 0.687 & 0.452 & 0.090 \\
\hline & 1 & 0.103 & & & & & \\
\hline EBT/TE & 0 & 0.925 & 0.985 & 0.124 & 0.530 & 0.908 & 0.000 \\
\hline & 1 & & & & & & \\
\hline $\mathrm{S} / \mathrm{TE}$ & 0 & 0.486 & 0.926 & 0.000 & 0.557 & 0.329 & 0.986 \\
\hline & 1 & & & & & & \\
\hline $\mathrm{TD} / \mathrm{TE}$ & 0 & 0.832 & 0.629 & 0.015 & 0.016 & 0.002 & 0.719 \\
\hline & 1 & & & & & & \\
\hline TE/TD & 0 & 0.890 & 0.681 & 0.926 & 0.693 & 0.486 & 0.002 \\
\hline & 1 & & & & & & \\
\hline TE/TA & 0 & 0.624 & 0.647 & 0.954 & 0.009 & 0.393 & 0.007 \\
\hline & 1 & 0.024 & & 0.934 & 0.007 & & \\
\hline TD/TA & 0 & 0.746 & 0.556 & 0.459 & 0.527 & 0.401 & 0.003 \\
\hline & 1 & & & & & & \\
\hline EBITDA/TA & 0 & 0.603 & 0.430 & 0.001 & 0.041 & 0.836 & 0.000 \\
\hline & 1 & & & & & & \\
\hline $\mathrm{EBIT} / \mathrm{S}$ & 0 & 0.000 & 0.000 & 0.000 & 0.906 & 0.609 & 0.000 \\
\hline & 1 & & & & & & \\
\hline EBITDA/TD & 0 & 0.293 & 0.184 & 0.003 & 0.168 & 0.258 & 0.000 \\
\hline $\mathrm{CP} / \mathrm{TA}$ & 0 & 0721 & & 0002 & & 0227 & $0=120$ \\
\hline GP/TA & 1 & 0.721 & 0.508 & 0.003 & 0.653 & 0.367 & 0.138 \\
\hline EBIT/TD & 0 & 0.072 & 0.527 & 0.000 & 0.170 & 0.185 & 0.000 \\
\hline EB11/1D & 1 & $0.0 / 2$ & 0.521 & 0.000 & $0.1 / 0$ & 0.185 & 0.000 \\
\hline
\end{tabular}


Figure 10: Performance measures and classification accuracies for trend models and the complete model

The validation procedure follows the same rules as explained in Figure 3. All of these models showed much lower Gini-coefficients, with the result that their applicability as forecasting tools seems questionable. The CM-model (2010) is not shown here, because it is the same as the AR-model (2010).

\begin{tabular}{|c|c|c|c|c|c|c|c|c|c|c|c|c|}
\hline & \multicolumn{4}{|c|}{ TR (2011) } & \multicolumn{4}{|c|}{ TR (2010) } & \multicolumn{4}{|c|}{ CM (2011) } \\
\hline & \multicolumn{2}{|c|}{2011} & \multicolumn{2}{|c|}{2010} & \multicolumn{2}{|c|}{2011} & \multicolumn{2}{|c|}{2010} & \multicolumn{2}{|c|}{2011} & \multicolumn{2}{|c|}{2010} \\
\hline & EG & VG & EG & VG & EG & VG & EG & VG & EG & VG & EG & VG \\
\hline Accuracy & 0.756 & 0.701 & 0.750 & 0,771 & 0.473 & 0.430 & 0.467 & 0.491 & 0.890 & 0.846 & 0.916 & 0.890 \\
\hline Type I Error & 0.594 & 1.000 & 0.792 & 0,683 & 0.385 & 0.488 & 0.292 & 0.244 & 0.698 & 0.805 & 0.979 & 0.756 \\
\hline Type II Error & 0.222 & 0.255 & 0.216 & 0,201 & 0.536 & 0.575 & 0.548 & 0.526 & 0.072 & 0.113 & 0.011 & 0.069 \\
\hline F-measure & 0.857 & 0.824 & 0.855 & 0,868 & 0.624 & 0.584 & 0.615 & 0.636 & 0.941 & 0.915 & 0.956 & 0.941 \\
\hline AUC & 0.630 & 0.357 & 0.503 & 0,636 & 0.581 & 0.487 & 0.665 & 0.690 & 0.759 & 0.638 & 0.690 & 0.801 \\
\hline Gini-coeff. & 0.260 & -0.286 & 0.005 & 0,273 & 0.162 & -0.026 & 0.330 & 0.380 & 0.518 & 0.276 & 0.380 & 0.602 \\
\hline AUC & \multicolumn{2}{|c|}{0.543} & \multicolumn{2}{|c|}{0.542} & \multicolumn{2}{|c|}{0.554} & \multicolumn{2}{|c|}{0.672} & \multicolumn{2}{|c|}{0.437} & \multicolumn{2}{|c|}{0.491} \\
\hline Gini-coeff. & \multicolumn{2}{|c|}{0.086} & \multicolumn{2}{|c|}{0.084} & & 07 & \multicolumn{2}{|c|}{0.345} & & 126 & \multicolumn{2}{|c|}{-0.018} \\
\hline AUC & \multicolumn{4}{|c|}{0.542} & \multicolumn{4}{|c|}{0.611} & \multicolumn{4}{|c|}{0.466} \\
\hline Gini-coeff. & \multicolumn{4}{|c|}{0.085} & \multicolumn{4}{|c|}{0.222} & \multicolumn{4}{|c|}{-0.068} \\
\hline
\end{tabular}

\section{REFERENCES}

Abidali, A. F. \& Harris, F., (1995), 'A methodology for predicting company failure in the construction industry', Construction Management and Economics, 13: 189 - 196.

Agarwal, V. \& Taffler, R., (2007), 'Twenty-five years of the Taffler z-core model: Does it really have predictive ability?', Accounting and Business Research, 37 (4): 285 - 300.

Ahn, B. S., Cho, S. S. \& Kim, C. Y., (2000), 'The integrated methodology of rough set theory and artificial neural network for business failure prediction', Expert Systems with Applications, 18: $65-74$.

Altman, E., I., Sabato, G. \& Wilson, N., (2010), 'The value of non-financial information in small and medium-sized enterprise risk management', The Journal of Credit Risk, 6 (2): 1 - 33.

Altman, E. I., Haldeman, R. G. \& Narayanan, P., (1977), 'ZETA ${ }^{\mathrm{TM}}$ analysis: A new model to identify bankruptcy risk of coprorations', Journal of Banking and Finance, 1: 29 - 54.

Altman, E. I., (1968), 'Financial ratios, discriminant analysis and the prediction of corporate bankruptcy', The Journal of Finance, 23: 589 - 609.

Anandarajan, M., Lee, P. \& Anandarajan, A., (2001), 'Bankruptcy prediction of financially stressed firms: An examination of the predictive accuracy of artificial neural networks', International Journal of Intelligent Systems in Accounting, Finance \& Management, 10: 69 - 81.

Anderson, R. ,(2007), The credit scoring toolkit: Theory and practice for retail credit risk management and decision automation, (Oxford: Oxford University Press).

Baetge, J., Beuter, H. \& Feidicker, M., (1992), 'Kreditwürdigkeitsprüfung mit Diskriminanzanalyse', Die Wirtschaftsprüfung, 24: 749 - 761.

Bates, T., (1990), 'Entrepreneur human capital inputs and small business longevity', The Review of Economics and Statistics, 72 (4): 551 - 559. 
Barniv, R., Agarwal, A. \& Leach, R., (2002), 'Predicting bankruptcy resolution', Journal of Business Finance \& Accounting, 29 (3 \& 4): $497-520$.

Barniv, R. \& McDonald, J. B., (1992), 'Identifying financial distress in the insurance industry: A synthesis of methodological and empirical issues', The Journal of Risk and Insurance, 59 (4): $543-574$.

Barniv, R. \& Raveh, A., (1989), 'Identifying financial distress: A new nonparametric approach', Journal of Business Finance \& Accounting, 16 (3): 361 - 383.

Beaver, W. H., Kettler, P. \& Scholes, M., (1970), 'The association between market determined and accounting determined risk measures', The Accounting Review, 45 (4): 654 - 682.

Beaver, W. H., (1966), 'Financial ratios as predictors of failure'. Journal of Accounting Research: Selected Studies, 4: $71-111$.

Begley, J., Ming, J. \& Watts, S., (1996), 'Bankruptcy classification errors in the 1980s: An empirical analysis of Altman's and Ohlson's models', Review of Accounting Studies, 1: 267 - 284.

Betts, J. \& Belhoul, D., (1987), 'The effectiveness of incorporating stability measures in company failure models', Journal of Business Finance \& Accounting, 14 (3): 323 - 334.

Blum, M., (1974), 'Failing company discriminant analysis', Journal of Accounting Research, 12 (1): $1-25$.

Bruse, H., (1978), 'Die Prognosefähigkeit von Kennzahlen bei verschiedenen Maßen für das Unternehmenswachstum', Zeitschrift für Betriebswirtschaft, 48: 138 - 152.

Bryant, S. M., (1997), 'A case-based reasoning approach to bankruptcy prediction modelling', Intelligent Systems in Accounting, Finance and Management, 6: 195 - 214.

Burns, R. B. \& Burns, R. A., (2008), Business research methods and statistics using SPSS, (London: Sage Publications).

Butera, G. \& Faff, R., (2006), 'An integrated multi-model credit rating system for private firms', Review of Quantitative Finance \& Accounting, 27: $311-340$.

Chancharat, N., Tian, G., Davy, P., McCrae, M. \& Lodh, S. (2010), 'Multiple states of financially distressed companies: Tests using a competing risk-model', Australasian Accounting Business and Finance Journal, 4 (4): 27 - 44.

Charitou, A., Neophytou, E. \& Charalambous, C., (2004), 'Predicting corporate failure: Empirical evidence for the UK', European Accounting Review, 13 (3): 465 - 497.

Chaudhuri, A., (2013), 'Bankruptcy prediction using Bayesian, hazard, mixed logit and rough Bayesian models: A comparative analysis', Computer and Information Science, 6 (2): 103 - 125.

Chava, S. \& Jarrow, R. A., (2004), 'Bankruptcy prediction with industry effects', Review of Finance, 8: $537-569$.

Chen, J., Marshall, B. R., Zhang, J. \& Ganesh, S., (2006), 'Financial distress prediction in China', Review of Pacific Basin Financial Markets and Policies, 9 (2): 317 - 336.

Cheng, W.-Y., Su, E. \& Li, S.-J., (2006), 'A financial distress pre-warning study by fuzzy regression model of TSE-listed companies', Asian Academy of Management Journal of Accounting and Finance, 2 (2): $75-93$.

Chi, L.-C. \& Tang, T.-C., (2006), 'Bankruptcy prediction: Application of logit analysis in export credit risks', Australian Journal of Management, 31 (1): 17 - 27.

Coats, P. K. \& Fant, F. L., (1993), 'Recognizing financial distress patterns using a neural network tool', Financial Management, 22: 142 - 155.

Cressy, R., (2006), 'Why do most firms die young?', Small Business Economics, 26: 103 - 116.

Dambolena, I. G. \& Khoury, S. J., (1980), 'Ratio stability and corporate failure', The Journal of Finance, 35 (4): 1017 - 1026.

DeAngelo, H. \& DeAngelo, L., (1990), 'Dividend policy and financial distress: An empirical investigation of troubled NYSE firms', The Journal of Finance, 45 (5): 1415 - 1431. 
Dietrich, J., Arcelus, F. J. \& Srinivasan, G., (2005), 'Predicting financial failure: Some evidence from new Brunswick agricultural co-ops', Annals of Public and Cooperative Economics, 76 (2): $179-194$.

Dimitras, A. I., Slowinski, R., Susmaga, R. \& Zopounidis, C., (1999), 'Business failure prediction using rough sets', European Journal of Operational Research, 114: 263 - 280.

Dirickx, Y. \& van Ladeghem, G., (1994), 'Statistical failure prevision problems', Tijdschrift voor Economie en Management. 39 (4): 429 - 462.

Drobetz, W. \& Wanzenried, G., (2006), 'What determines the speed of adjustment to the target capital structure?', Applied Financial Economics, 16: 941 - 958.

Du Jardin, P., (2009), 'Bankruptcy prediction models: How to choose the most relevant variables?', Bankers, Markets \& Investors, 98: 39 - 46.

Edmister, R. O., (1972), 'An empirical test of financial ratio analysis for small business failure prediction', Journal of Financial and Quantitative Analysis, 7: 1477 - 1493.

Fanning, K. M. \& Cogger, K. O., (1994), 'A comparative analysis of artificial neural networks using financial distress prediction', Intelligent Systems in Accounting, Finance and Management, 3: $241-252$.

Fawcett, T., (2006), 'An introduction to ROC analysis', Pattern Recognition Letters, 27: 861 - 874.

Feldesman, M. R., (2002), 'Classification trees as an alternative to linear discriminant analysis', American Journal of Physical Anthropology, 119: 257 - 275.

Frydman, H., Altman, E. I. \& Kao, D.-L., (1985), 'Introducing recursive partitioning for financial classification: The case of financial distress', The Journal of Finance, 40 (1): $269-291$.

Gilbert, L. R., Menon, K. \& Schwartz, K. B., (1990), 'Predicting bankruptcy for firms in financial distress', Journal of Business Finance \& Accounting, 17 (1): 161 - 171.

Gombola, M. J., Haskins, M. E., Ketz, E. J. \& Williams, D. D., (1987), 'Cash flow in bankruptcy prediction', Financial Management, 16: 55 - 65.

Grunert, J., Norden, L. \& Weber, M., (2005), 'The role of non-financial factors in internal credit ratings', Journal of Banking \& Finance, 29: 509 - 531.

Hanley, J. \& McNeil, B., (1983), 'A method of comparing the areas under receiver operating characteristic curves derived from the same cases', Radiology, 148 (3): 839 - 843.

Hanley, J. \& McNeil, B., (1982), 'The meaning and the use of the area under a receiver operating characteristic (ROC) curve', Radiology, 143 (1): 29 - 36.

Hauschildt, J., Rösler, J. \& Gemünden, H. G., (1984), 'Der Cash Flow - Ein Krisensignalwert?', Die Betriebswirtschaft, 44 (3): 353 - 370.

Hauser, R. P. \& Booth, D., (2011), 'Predicting bankruptcy with robust logistic regression', Journal of Data Science, 9: 565 - 584

Herzog, S., Koziol, C. \& Thabe, T., (2008), 'Optimal credit ratings', International Journal of Theoretical and Applied Finance, 11 (2): 225 - 247.

Hillegeist, S. A., Keating, E. K., Cram, D. P. \& Lundstedt, K. G., (2004), 'Assessing the probability of bankruptcy', Review of Accounting Studies, 9: 5 - 34.

Ho, R., (2006), Handbook of univariate and multivariate data analysis and interpretation with SPSS, (Boca Raton: Chapman \& Hall).

Hong, H. \& Rappaport, A., (1978), 'Debt capacity, optimal capital structure, and capital budgeting analysis', Financial Management, 7 (3): 7 - 11.

Hopwood, W. S. \& Schaefer, T. F., (1988b), 'Incremental information content of earnings and nonearnings-based financial ratios', Contemporary Accounting Research, 5 (1): 318 - 342.

Hopwood, W., McKeown, J. \& Mutchler, J., (1988a), 'The sensitivity of financial distress prediction models to departures from normality', Contemporary Accounting Research, 5 (1): 284 - 298.

Houghton, K. A. \& Woodliff, D. R., (1987), 'Financial ratios: The prediction of corporate 'success' and failure', Journal of Business Finance \& Accounting, 14 (4): 537 - 554. 
Huang, S.-H., Tsai, C.-F., Yen, D.C. \& Cheng, Y.-L., (2008), 'A hybrid financial analysis model for business failure prediction', Expert Systems with Applications, 35: 1034 - 1040.

Iazzolini, G., Migliano, G. \& Gregorace, E., (2013), 'Evaluating intellectual capital for supporting credit risk assessment: An empirical study', Investment Management and Financial Innovations, 10 (2): $44-54$.

Kahya, E. \& Theodossiou, P., (1999), 'Predicting corporate financial distress: A time-series CUSUM methodology', Review of Quantitative Finance and Accounting, 13: 323 - 345.

Kane, G. D., Richardson, F. M. \& Meade, N. L., (1998), 'Rank transformation and the prediction of corporate failure', Contemporary Accounting Research, 15 (2): 145 - 166.

Kim, H. \& Gu, Z., (2006), 'Predicting restaurant bankruptcy: A logit model in comparison with a discriminant model', Journal of Hospitality \& Tourism Research, 30 (4): 474 - 493.

Klecka, W. R., (1980), Discriminant analysis, (Newbury Park: SAGE)

Korol, T. \& Korodi, A., (2011), 'An evaluation of effectiveness of fuzzy logic model in predicting the business bankruptcy', Romanian Journal of Economic Forecasting, 3: 92 - 107.

Laitinen, E. K. \& Laitinen, T., (2000), 'Bankruptcy prediction: Application of the Taylor's expansion in logistic regression', International Review of Financial Analysis, 9: 327 - 349.

Lambert, R., Leuz, C. \& Verrechia, R. E., (2007), 'Accounting information, disclosure, and the cost of capital', Journal of Accounting Research, 45 (2): 385 - 420.

Lau, A. H.-L., (1987), 'A five-state financial distress prediction model', Journal of Accounting Research, 25 (1): 127 - 138.

Li, H., Sun, J. \& Wu, J., (2010), 'Predicting business failure using classification and regression tree: An empirical comparison with popular classical statistical methods and top classification mining methods', Expert Systems with Applications, 37: 5895 - 5904.

Li, J., (2012), 'Prediction of corporate bankruptcy from 2008 through 2011', Journal of Accounting and Finance, 12 (1): $31-41$.

Liang, H.-Y. \& Bathala, C., (2009), 'Tradeoff or pecking order: Capital structure policy suitable for financially distressed firms', The IUP Journal of Applied Finance, 15 (10): 5 - 18.

Lin, F., Liang, D. \& Chen, E., (2011), 'Financial ratio selection for business crisis prediction', Expert Systems with Applications, 38: 15094 - 15102.

Lin, R.-H., Wang, Y.-T., Wu, C.-H. \& Chuang, C.-L., (2009), 'Developing business failure prediction model via RST, GRA and CBR', Expert Systems with Applications, 36: 1593 - 1600.

Low, S.-W., Nor, F. M. \& Yatim, P., (2001), 'Predicting corporate financial distress using the logit model: The case of Malaysia', Asian Academy of Management Journal, 6 (1): 49 - 61.

Madrid-Guijarro, A., Garcia-Pèrez-de-Lema, D. \& van Auken, H., (2011), 'An analysis of non-financial factors associated with financial distress', Entrepreneurship \& Regional Development, $23(3-4): 159-186$.

Martin, J. D. \& Scott, D. F. (1976), 'Debt capacity and the capital budgeting decision', Financial Management, 5 (2): 7 - 14 .

McKee. T. E., (2007), 'Altman's 1968 bankruptcy prediction model revisited via genetic programming: New wine from an old bottle or a better fragmentation process?', Journal of Emerging Technologies in Accounting, 4: 87 - 101.

McLachlan, G. J., (2004), Discriminant analysis and statistical pattern recognition, (New Jersey: John Wiley \& Sons).

Mensah, Y. M., (1984), 'An examination of the stationarity of multivariate bankruptcy prediction models: A methodological study', Journal of Accounting Research, 22 (1): 380 - 395.

Milburn, A. J., (2008), 'The relationship between fair value, market value, and efficient markets', Accounting Perspectives, 7 (4): 293 - 316.

Min, J. H. \& Lee, Y.-C., (2008), 'A practical approach to credit scoring', Expert Systems with Applications, 35: $1762-1770$. 
Molina, C. A. \& Preve, L. A., (2009), 'Trade receivables policy of distressed firms and its effect on the costs of financial distress', Financial Management, 38 (3): 663 - 686.

Molina, C. A., (2005), 'Are firm underleveraged? An examination of the effect of leverage on default probabilities', The Journal of Finance, 60 (3): 1427 - 1459.

Mossman, C. E., Bell, G. G., Swartz, L. M. \& Turtle, H., (1998), 'An empirical comparison of bankruptcy models', The Financial Review, 33: 35 - 54.

Muller, G. H., Steyn-Bruwer, B. W. \& Hamman, W. D., (2009), 'Predicting financial distress of companies listed on JSE - A comparison of techniques', South African Journal of Business \& Management, 40 (1): 21 - 32.

Nam, J.-H. \& Jinn, T., (2000), 'Bankruptcy prediction: Evidence from Korean listed companies during the IMF crisis', Journal of International Financial Management and Accounting, 11 (3): $178-197$.

Neopyhtou, E. \& Mar Molinero, C., (2004), 'Predicting corporate failure in the UK: A multidimensional scaling approach', Journal of Business Finance \& Accounting, 31 (5 \& 6): 677 - 710.

Neves, J. C. \& Vieira, A., (2006), 'Improving bankruptcy prediction with hidden layer learning vector quantization', European Accounting Review, 15 (2): 253 - 271.

Nissim, D. \& Penman, S. H., (2003), 'Financial statement analysis of leverage and how it informs about profitability and price-to-book ratios', Review of Accounting Studies, 8: 531 - 560.

Ohlson, J. A., (1980), 'Financial ratios and the probabilistic prediction of bankruptcy', Journal of Accounting Research, 18 (1): 109 - 131.

Pacey, J. W. \& Pham, T. M., (1990), 'The predictiveness of bankruptcy models: Methodological problems and evidence', Australian Journal of Management, 15 (2): 315 - 337.

Pang, J. \& Kogel, M., (2013), 'Retail bankruptcy prediction', American Journal of Economics and Business Administration, 5 (1): 29 - 46.

Paradi, J. C., Asmild, M. \& Simak, P. C., (2004), 'Using DEA and worst practice DEA in credit risk evaluation', Journal of Productivity Analysis, 21: 153 - 165.

Pervan, I. \& Kuvek, T., (2013), 'The relative importance of financial ratios and nonfinancial variables in predicting of insolvency', Croatian Operational Research Review, 4: 187 - 198.

Pervan, I., Pervan, M. \& Vukoja, B., (2011), 'Prediction of company bankruptcy using statistical techniques - Case of Croatia', Croatian Operational Research Review, 2: 158 - 167.

Pervan, M. \& Visic, J., (2012), 'Influence of firm size on its business success', Croatian Operational Research Review, 3: 213 - 223.

Piotroski, J. D., (2000), 'Value investing: The use of historical financial statement information to separate winners from loser', Journal of Accounting Research, 38: 1 - 41.

Pindado, J., Rodrigues, L. \& de la Torre, C., (2008), 'Estimating financial distress likelihood', Journal of Business Research, 61: 995 - 1003.

Platt, H. D. \& Platt, M. B., (2008), 'Financial distress comparison across three global regions', Journal of Risk and Financial Management, 1: 129 - 162.

Platt, H. D. \& Platt, M. B., (2002), 'Predicting corporate financial distress: Reflections on choice-based sample bias', Journal of Economics and Finance, 26: 184 - 199.

Platt, H. D., Platt, M. B. \& Chen, G., (1995), 'Sustainable growth rates of firms in financial distress', Journal of Economics and Finance, 19 (2): 147 - 151

Pompe, P. P. \& Bilderbeek, J., (2005), 'Bankruptcy prediction: The influence of the year prior to failure selected for model building and the effects in a period of economic decline', Intelligent Systems in Accounting, Finance and Management, 13: 95 - 112.

Prasad, D. \& Puri, Y. R., (2005), 'Does combining alternate bankruptcy prediction models improve forecasting accuracy?', The International Journal of Finance, 3: 3581 - 3602.

Pretorius, M., (2008), 'Critical variables of business failure: A review and classification framework', South African Journal of Economic and Management Sciences, 11 (4): 408 - 430. 
Raykov, T. \& Marcoulides, G. A., (2008), Introduction to applied multivariate analysis, (New York:

Sachs, L., (1997), Angewandte Statistik: Anwendung statistischer Methoden, (Berlin-Heidelberg: Springer).

Samad, F., Yusof, M. A. M. \& Shaharudin, R. S., (2009), 'Financial distress risk and stock returns: Evidence form the Malaysian stock market', Journal of International Finance and Economics, 9 (2): $19-38$.

Schneider, D., (1995), 'Eine Warnung vor Frühwarnsystemen', Der Betrieb, 38 (9): 1489 - 1494.

Sen, T. K., Ghandforoush, P. \& Stivason, C. T., (2004), 'Improving prediction of neural networks: A study of two financial prediction tasks', Journal of Applied Mathematics and Decision Sciences, 8 (4): $219-233$.

Setiono, B. \& Strong, N., (1998). 'Predicting stock returns using financial statement information', Journal of Business Finance \& Accounting, 25 (5 \& 6): 631 - 657.

Shin, K-S., Lee, T. S. \& Kim, H.-j., (2005), 'An application of support vector machines in bankruptcy prediction model', Expert Systems with Applications, 28: 127 - 135.

Shumway, T., (2001), 'Forecasting bankruptcy more accurately: A simple hazard model', The Journal of Business, 74 (1): 101 - 124.

Silva, D. A. P., Stam, A. \& Neter, J., (2002), 'The effects of misclassification cost and skewed distributions in two-group classification', Communication in Statistical Simulation, 31 (3): 401 - 423.

Situm, M., (2014b), 'The inability of gearing-ratio as predictor for early warning systems', Business Systems Research Journal, 5 (2): 23 - 45.

Situm, M., (2014a), 'The age and the size of the firm as relevant predictors for bankruptcy', Journal of Applied Economics and Business, 2 (1): 5 - 30.

Situm, M., (2008), Insolvenzfrüherkennung mit der Diskriminanzanalyse: Grundlagen, Ansätze, praktische und theoretische Relevanz, (Saabrücken: Dr. Müller Verlag).

Sobehart, J., Keenan, S. \& Stein, R., (2001), 'Benchmarking quantitative default risk model: A validation methodology', Algo Research Quarterly, 4 (1 \& 2): 57 - 71.

Skogsvik, K. \& Skogsvik, S., (2013), 'On the choice based sample bias in probabilistic bankruptcy prediction', Investment Management and Financial Innovation, 10 (1): 29 - 37.

Subhash, S., (1996), Applied multivariate techniques, (New York: John Wiley \& Sons).

Sudarsanam, S. \& Lai, J., (2001), 'Corporate financial distress and turnaround strategies: An empirical analysis', British Journal of Management, 12: 183 - 199.

Theodossiou, P., Kahya, E., Saidi, R. \& Philippatos, G., (1996), 'Financial distress and corporate acquisitions: Further empirical evidence', Journal of Business Finance \& Accounting, 23 (5 \& 6): $699-719$.

Thomas, L. C., Edelman, D. B. \& Crook, J. N., (2002), Credit scoring and its applications, (Philadelphia: SIAM).

Thornhill, S. \& Amit, R., (2003), 'Learning about failure: Bankruptcy, firm age, and the resource-based view', Organization Science, 14 (5): 497 - 509.

Tsai, B.-H., (2013), 'An early warning system of financial distress using multinomial logit models and a bootstrapping approach', Emerging Markets Finance \& Trade, 49 (2): 43 - 69.

Tsai, L.-K., Tserng, H.-P., Liao, H.-H., Chen, P.C. \& Wang, W.-P., (2012), 'Integration of accounting-based and option-based models to predict construction contractor default', Journal of Marine Science and Technology, 20 (5): 479 - 484.

Turetsky, H. F. \& McEwen, R. A., (2001), 'An empirical investigation of firm longevity: A model of the ex ante predictors of financial distress', Review of Quantitative Finance and Accounting, 16: $323-343$.

Wang, W. T. \& Zhou, X., (2011), 'Could traditional financial indicators predict the default of small and medium-sized enterprises?', International Conference on Economics and Finance Research, 4: $72-76$ 
Ward, T. J., (1999), 'A review of financial distress research methods and recommendations for future research', Academy of Accounting and Financial Studies Journal, 3 (1): 160 - 178.

Whitaker, R. B., (1999), 'The early stages of financial distress', Journal of Economics and Finance, 23 (2): $123-133$.

Wilson, N., Chong, K. W. \& Peel, M. J. (1995), 'Neural network simulation and the prediction of corporate outcomes: Some empirical findings', International Journal of Economics of Business, 2 (1): $31-50$.

Yeh, C.-C., Chi, D.-J. \& Hsu, M.-F., (2010), 'A hybrid approach of DEA, rough set and support vector machines for business failure prediction', Expert Systems with Applications, 37: 1535 - 1541.

Yim, J. \& Mitchell, H., (2007), 'Predicting financial distress in the Australian financial service industry', Australian Economic Papers, 46 (4): 375 - 388.

Yip, A. Y. N., (2006), 'Business failure prediction: A case-based reasoning approach', Review of Pacific Basin Financial Markets and Policies, 9 (3): 491 - 508.

Youn, H. \& Gu, Z., (2010), 'Predict US restaurant firm failures: The artificial neural network model versus logistic regression model', Tourism and Hospitality Research, 10: 171 - 1k87.

Zmijewski, M. E., (1984), 'Methodological issues related to the estimation of financial distress prediction models', Journal of Accounting Research, 22: 59 - 82. 